\title{
From scientific experiments to innovation: impact pathways of a Synchrotron Light Facility
}

Gelsomina Catalano $^{1 *}$, Gaston García López ${ }^{2}$, Alejandro Sánchez ${ }^{3}$ and Silvia Vignetti ${ }^{1}$

\author{
Affiliations: \\ ${ }^{1}$ CSIL - Centre for Industrial Studies (Milan, Italy) \\ ${ }^{2}$ Centro de Micro-Análisis de Materiales, Universidad Autónoma de Madrid (Madrid, Spain) and Alba Synchrotron \\ Light Source (Barcelona, Spain) \\ ${ }^{3}$ Alba Synchrotron Light Source (Barcelona, Spain)
}

*Corresponding Author: Gelsomina Catalano (catalano@csilmilano.com)

\begin{abstract}
$^{1}$
Research infrastructures are commonly used by scientific and industrial communities to conduct research and experiments which translate in the creation of new knowledge. This knowledge may generate different outcomes (e.g. publications, patents, etc.) and find applications in different sectors and domains, ultimately triggering innovation developments. However, the pathway from knowledge creation to innovation is complex: it is split among different players, from the scientific community to industrial actors (even those not directly involved in the experiments) and may take time and significant investments.
\end{abstract}

The objective of this paper is to assess innovation impacts arising from a Research Infrastructure and specifically tracing and describing the pathways according to which these impacts may materialize. The example used is the ALBA Synchrotron Light source facility located in Barcelona and in operation since 2012 .

The paper builds on the evidence collected through two surveys to direct and indirect users of ALBA (overall 384 questionnaires collected), in-depth interviews as well as an analysis of patents' citations. It draws from a pilot exercise carried out in the framework of the Horizon 2020 Ri-Paths project. It contributes to the broader discussion on the socio-economic impact assessment of Research Infrastructures and relevant methodologies and metrics.

Keywords: research infrastructures, impact assessment, innovation pathways.

\footnotetext{
${ }^{1}$ Acknowledgments: This paper draws from a pilot activity carried out in the frame of the research project 'Charting Impact Pathways of Investment in Research Infrastructures' addressed to develop a framework describing the socio-economic impact of research infrastructures and co-financed by the European Union's Horizon 2020 research and innovation programme under the grant agreement No 777563, whose financial support is gratefully acknowledged. Further details can be found at: https://ri-paths.eu/

The authors are grateful to Inmaculada Ramos Lerate, Núria Madrid and Marta Ávila Pérez from ALBA - for the support provided for the dissemination of the survey to ALBA users as well as to Alessandra Caputo and Chiara Pancotti - for collaboration in data analysis and processing. They are also grateful to all people who have contributed to informing this paper by replying to the survey and/or accepting an interview.
} 


\section{Introduction}

Research infrastructures (RIs) are something more complex than single laboratories where knowledge is created and shared with multiple users. As defined by the European Union Horizon 2020 work program for science, they are facilities, resources, and services - single-sited, virtual or distributed - that are used by the research communities to conduct research and foster innovation in their fields (European Commission 2017a). However, innovation impacts arising from research/experiment carried out at the RI might not be immediate. The pathway to innovation meant as the chain of events that connects the knowledge creation (arisen from the use of RI) to identifiable effects - is a rather complex process involving different players and entailing further time and investments (Catalano et al. 2020, ESFRI 2018). Even when the user is a private company, the latter can act as a research service provider for third parties interested in developing an innovation output (e.g. an innovative device/treatment) based on research carried out at the RI.

This paper provides an example of available metrics for assessing these innovation impacts and describes the pathways according to which they materialize. It specifically attempts to provide an answer to the following evaluation questions by taking the example of ALBA Synchrotron Light source facility ${ }^{2}$.

- How can innovation outputs arising from the use of research infrastructures be measured?

- In which fields and through which pathways innovations stemming from experiments at RIs are likely to materialize?

- What is/are the gestation lag(s) of innovation, such as the time lag between the experiment and the development of an innovation output with economic or practical significance?

- What is/are the research gap(s) of innovation, such as the additional research activities needed to develop an innovation output with economic or practical significance?

ALBA - located in Cerdanyola del Vallès (Barcelona) - is an example of single-sited research infrastructure, specifically an accelerator-based photon source facility which provides eight experimental beamlines allowing for investigations in different scientific fields (e.g., chemistry, pharmaceutical, health products, etc.). These experiments - carried out both by users from the scientific community and private companies - may translate in different outcomes (e.g., publications, patents, etc.) likely to find applications and trigger innovation developments in a wide and diverse range of fields (e.g., packaging, automotive, food, geoscience, etc.). The majority of users are from the scientific community; only a minor share are private companies. Even when the experiment does not involve the industrial sectors directly, results can generate an impact on the

\footnotetext{
${ }^{2}$ www.albasynchrotron.es
} 
industry after some time has elapsed, and some additional research activities or other investments are carried out. ALBA synchrotron is part of the League of European Accelerator-based Photon Sources (LEAPS) ${ }^{3}$ which includes many other existing synchrotrons and free-electron lasers likely to spill over and trigger innovation. In addition, through LEAPS, ALBA is part of the Analytical Research Infrastructures of Europe (ARIE) network which includes seven Europe-wide RI networks providing state-of-the-art analytical facilities for Europe's researchers ${ }^{4}$.

This paper draws from the evidence collected through a pilot exercise ${ }^{5}$ carried out by the Centre for Industrial Studies (hereafter CSIL) and ALBA synchrotron in the framework of the Horizon 2020 Ri-Paths project ${ }^{6}$. Specifically, it builds on 384 questionnaires - collected through two surveys carried out (from December 2019 to March 2020) to direct and indirect users of ALBA beamlines $^{7}$ - in-depth interviews with ALBA users as well as an analysis of patents' citations. This methodological approach draws from the conceptual framework proposed by Florio (2019) for assessing the innovation impacts generated by ALBA. Specifically, our analysis looked at the pathways materializing from the design to the performance of the experiment as well as to generation of the innovation output and its impacts.

After this brief introduction, the paper is structured as follows: Section 2 discusses the innovation "ecosystem" related to a research infrastructure with the objective to better frame the focus of this paper; Section 3 presents ALBA Synchrotron Light Source facility and its research activities; Section 4 describes the methodological approach adopted for the assessment of innovation impacts generated by ALBA; Section 5 discusses the results while Section 6 concludes.

\section{The innovation ecosystem of RIs}

Whether funded and operating on regional, national or EU level, RIs have a key role in advancing, exploiting and disseminating knowledge and technology development and provide an important link in the innovation chain (Interreg Europe 2019, ESFRI 2017). Two-thirds of the EU's economic growth derives from research and innovation, accounting for $15 \%$ of all productivity

\footnotetext{
${ }^{3}$ This is a consortium of all European accelerator-based photon based on a declaration that was signed by the 16 member institutions in 2017 . The primary goal of LEAPS is to actively and constructively ensure and promote the quality and impact of the fundamental, applied and industrial research carried out at their respective facilities to the greater benefit of European science and society. More details are available at https://leapsinitiative.eu/.

${ }^{4}$ The ARIE network accounts for a growing and diverse user community of more than 40,000 researchers in academia and industry, across a range of domains: the physical sciences, energy, engineering, the environment and the earth sciences, as well as medicine, health, food and cultural heritage. More details are available at https://www.ionbeamcenters.eu/analytical-research-infrastructures-aries-position-paper-horizon-europe-missions/ 5 See Catalano, J. et al. (2020), The pathways from experiments to innovation impacts: evidence from ALBA Synchrotron Light Facility, available at https://ri-paths.eu/wp-content/uploads/2020/06/T5.2_Pilot-IA-project-with-ALBA.pdf

6 The project was created to develop a framework describing the socio-economic impacts of research infrastructures activities. More details are available at https://ri-paths.eu/ (Grant agreement No 777563).

${ }^{7}$ In this paper, direct users are referred to those accessing physically the facility or being part, even remotely, of the team carrying out the experiment. Indirect users are third parties who have used results from experiments carried out at ALBA without being involved in their design and performance; they have usually known about these results through publications or from colleagues, etc.
} 
gains in Europe (European Commission, 2017b) and RIs are found to be an essential pillar of this development (ESFRI, 2020; OECD, 2019).

In terms of organisation, RIs can be single-sited (unified single body of equipment at one single physical location), distributed (a network of distributed resources: instrumentation, collections, archives, and scientific libraries) or virtual (the service is provided electronically) facilities (Science Global Forum OECD 2014 and 2016; OECD 2014, ESFRI 2010 ERIC Council Regulation No 723/2009, European Union Regulation No 1291/2013). However, regardless the type of organisation, these facilities are not stand-alone installations; they entail a broad range of interactions with the surrounding economic and industrial environment, thus providing potential opportunities for innovation. For instance, in the construction and major upgrade stages, industry may interact with RIs as a provider of state-of-the-art technologies, new designs, components, software, etc. under standard procurement conditions or in closer collaborative conditions. During the operation phase, industry can also be a user, often in cooperation with academic teams, of the experimental facilities and of the data for early-stage basic research, for more applied industrial research and/or for testing innovative developments and products. Three types of interactions can occur between the RIs and industry through which innovation is potentially generated: procurement activities, technology transfer/licencing agreement and provision of specific services or data (Helman, A. 2020). The mix of such interactions, their absence or presence, as well as their intensity and relevance vary substantially depending on the nature of the RI and the strategic objectives that the RI is pursuing (ESFRI 2017).

Several studies (e.g., Åberg et al. 2015, Florio et al. 2018, etc.) have been investigating the innovation occurring upstream through procurement activities related interactions. For instance, Florio et al. (2018) found - through a Bayesian network analysis ${ }^{8}$ of survey data on about 670 firms - that collaborative relations between CERN and its suppliers improve suppliers' performance and increase positive technological spillovers along the supply chain. Similarly, by gathering balancesheet data for more than 350 CERN LHC suppliers from 1991 to 2014, Castelnovo et al. (2018) found that becoming a CERN supplier induced greater R\&D effort and innovative capacity, thus enhancing productivity and profitability. Comin et al. (2018) - by using the production function approach - showed that the firms interacting through research contracts with FraunhoferGesellschaft increased their performance.

\footnotetext{
${ }^{8}$ It is an advanced but relatively intuitive approach that combines graphical map analysis with statistical analysis to show the probabilistic relationship among a set of variables and their conditional independences.
} 
Differently, the focus of this paper is on innovation impacts occurring downstream, such as those on industrial users which - directly or indirectly - benefit from resources and services provided by the RIs. Indeed, the latter might comprise a broad range of resources - such as scientific research equipment, collections, archives or scientific data, computing systems, communication networks, as well as pilot and demonstration sites, living labs, and more - which are used by a large community and which also represent potential routes to innovation. Also, there are RIs which welcome a high flux of peer-reviewed proposals and experiments involving industrial users, thus stimulating international collaborations and where several scientific disciplines and economic sectors cross together - physics, chemistry, biology, Earth sciences, energy, cultural heritage, food, etc. (ESFRI 2018).

The relation between the RIs and innovation is, however, diverse and often complex; there is no one-size-fits-all model or pathway (ESFRI 2017, 2018, Helman et al. 2020, Catalano et al. 2020). As pointed out by Florio (2019), the benefits of knowledge created by RIs might accrue to users more indirectly, through a chain of downstream transmission mechanisms. Third parties such as business in different industries, medical facilities, and government agencies acquire knowledge from experiments and observations in RIs through published results, and then adapt such knowledge to their specific needs. The example of synchrotron light source (SL) provides a clearer picture on how the knowledge can spread directly and indirectly from research infrastructure to users. SL is a set of accelerators (a linear accelerator, a booster, a storage ring) where electromagnetic radiation is created. This radiation has several desirable properties which might find applications in different fields (e.g., from condensed matter physics and materials sciences to pharmaceutical research and cultural heritage). Direct users - performing experiments on the synchrotrons - are usually researchers using the facility - including scientists hired by research hospitals, universities - or firms. Results from experiments carried out by direct users are then disseminated through publications or open-access database and used by third parties to develop an innovative product or may contribute to improve existing production processes which can translate, after further steps and time, into innovation.

Some attempts to track the innovation arising downstream through users of RIs are provided by that stream of literature focusing on patents and related citation impacts. For instance, Bousfield et al. 2016 investigated citations of bimolecular data resources (e.g., from the European Nucleotide Archive and the Protein Data Bank) in patent documents. They found citations in more than 8,000 patents from 2014, thus demonstrating substantial use and an important role for data resources in defining biological concepts in granted patents to both academic and industrial innovator. While being informative, this strategy is found to be constrained by the fact that many innovations are not 
patented. A more promising strategy (suggested by Florio, 2019) is a periodical survey of external users aimed to track the applications of their published research.

\section{Presenting ALBA Synchrotron}

ALBA is a third-generation Synchrotron Light facility located in Cerdanyola del Vallès (Barcelona), funded in equal parts by the Spanish and Catalan governments. Its construction began in 2006; the building was ready by 2009 while the accelerator in 2011; the first seven beamlines were commissioned by 2011-12; first users were hosted in 2012. The facility consists of the accelerator system providing $3 \mathrm{GeV}$ electron beam and currently eight experimental beamlines (see Table 1). ALBA can potentially host more beamlines (around 12 beamlines more). Indeed, four new beamlines are under construction, an additional one is under design, and further beamlines are expected to be approved during the following years ${ }^{9}$.

Table 1 ALBA beamlines and their scientific applications

\begin{tabular}{|c|c|c|c|}
\hline BEAMLINE & EXPERIMENTAL TECHNIQUES & SCIENTIFIC APPLICATIONS & $\begin{array}{l}\text { Start of } \\
\text { operation }\end{array}$ \\
\hline BL01-MIRAS & Infrared microspectroscopy & $\begin{array}{l}\text { Life sciences, food sciences, materials science, cultural } \\
\text { heritage }\end{array}$ & 2016 \\
\hline BL04-MSPD & $\begin{array}{l}\text { High-resolution powder diffraction } \\
\text { Microdiffraction including high pressure }\end{array}$ & $\begin{array}{l}\text { Structure of materials } \\
\text { Time-resolved diffraction } \\
\text { Quantitative phase analysis }\end{array}$ & 2012 \\
\hline $\begin{array}{l}\text { BL09- } \\
\text { MISTRAL }\end{array}$ & $\begin{array}{l}\text { Soft X-ray full-field transmission X-ray microscopy. } \\
\text { Optimized on the 'water window'. }\end{array}$ & $\begin{array}{l}\text { Cryogenic tomography of biological objects. Spatially } \\
\text { resolved spectroscopy }\end{array}$ & 2012 \\
\hline $\begin{array}{l}\text { BL11-NCD- } \\
\text { SWEET }\end{array}$ & $\begin{array}{l}\text { High-resolution small and wide-angle } \\
\text { X-ray scattering/diffraction }\end{array}$ & $\begin{array}{l}\text { Structure and phase transformations of } \\
\text { biological fibres, polymers, solutions } \\
\text { Time-resolved X-ray studies }\end{array}$ & 2012 \\
\hline BL13-XALOC & $\begin{array}{l}\text { X-ray diffraction from crystals of } \\
\text { biological macromolecules }\end{array}$ & $\begin{array}{l}\text { Macromolecular crystallography, with particular } \\
\text { emphasis on a large unit cell crystal }\end{array}$ & 2012 \\
\hline BL22-CLAESS & EXAFS, XANES, Quick-EXAFS, XES & $\begin{array}{l}\text { Materials science, catalysis, environmental } \\
\text { sciences, electronic structures }\end{array}$ & 2012 \\
\hline BL24-CIRCE & $\begin{array}{l}\text { Photoemission microscopy (PEEM) } \\
\text { Near-atmospheric-pressure photoemission (NAPP) }\end{array}$ & $\begin{array}{l}\text { Nano-science and magnetic domain imaging (PEEM). } \\
\text { Surface chemistry (NAPP) }\end{array}$ & 2012 \\
\hline BL29-BOREAS & $\begin{array}{l}\text { Circular magnetic dichroism } \\
\text { Resonant magnetic diffraction }\end{array}$ & $\begin{array}{l}\text { Magnetism, surface magnetism and magnetic } \\
\text { structures }\end{array}$ & 2012 \\
\hline
\end{tabular}

\footnotetext{
${ }^{9}$ Source: ALBA Activity Report, 2017
} 
A fraction of beamtime is booked for internal ALBA researchers for their own studies (around $13 \%$ ); $20 \%$ is reserved for testing and buffering (including reserve beamtime for proprietary access), while all the remaining beamtime, over two thirds, is for external users from academia field (meaning peer review access) ${ }^{10}$.

Overall, from 2012 to $2020,4,793$ users have benefitted from the use of beamtime at ALBA $^{11}$, coming from 821 different institutions. 94\% of ALBA users are researchers from public institutions, including university, research institutes, hospitals, etc. These users are granted free beamtime if their proposal has a proven scientific validity and if their scientific results are made publicly available. A minor share of beamtime (around 2\%) is given to business (e.g., industry, and private companies) for proprietary R\&D. ${ }^{12}$ It is worth mentioning that $56 \%$ of all users are from Spain while the remaining $44 \%$ are users from abroad ${ }^{13}$.

Overall, 1,381 proposals have been granted between 2013 and 2019 out of 2,494 submitted: only half of the applications per year are accepted on average with wide differences across beamlines (e.g., CIRCE, the photoemission spectroscopy and microscopy beamline, is in high demand and more than two-thirds of the proposals cannot be accepted).

Both the number of users and of proposals have increased over the years: 2,199 users accessed ALBA in 2019 which represents a significant increase compared to 2012 (339 users) while the number of proposals submitted exceeded 500 in 2019 compared to 180 in 2013 (see Figure 1).

\footnotetext{
${ }^{10}$ ALBA organises - twice a year - calls for proposals to grant the use of beamtime. Each proposal is reviewed by a team of international experts who assess its merit, also considering technical and safety aspects.

${ }^{11}$ Source: ALBA. It is worth noting that it may happen that users apply for beamtime in the framework of more than one experiment, e.g. by submitting a proposal every year for a different experiment.

${ }^{12}$ These users pay EUR 573.68 per hour. Source: https://www.cells.es/en/about/2019-rates-of-utilization

${ }^{13}$ Specifically 29\% from other EU Member States (Austria, Belgium, Croatia, Czech Republic, Denmark, Estonia, Finland, France, Germany, Greece, Hungary, Ireland, Italy, Latvia, Luxembourg, Netherlands, Poland, Portugal, Slovakia, Slovenia, Sweden) and 15\% from other countries (Argentina, Australia, Bosnia And Herzegovina, Brazil, Canada, Chile, China, Colombia, Egypt, India, Iran (Islamic Republic Of), Israel, Japan, Jordan, Korea, Republic of Mexico, Norway, Oman, Pakistan, Russian Federation, Saudi Arabia, Serbia, Singapore Switzerland, Taiwan, Turkey, Ukraine, United Kingdom, United States, Uruguay and Venezuela).
} 
Figure 1. The use of ALBA beamlines over the years: number of users and submitted/granted proposals
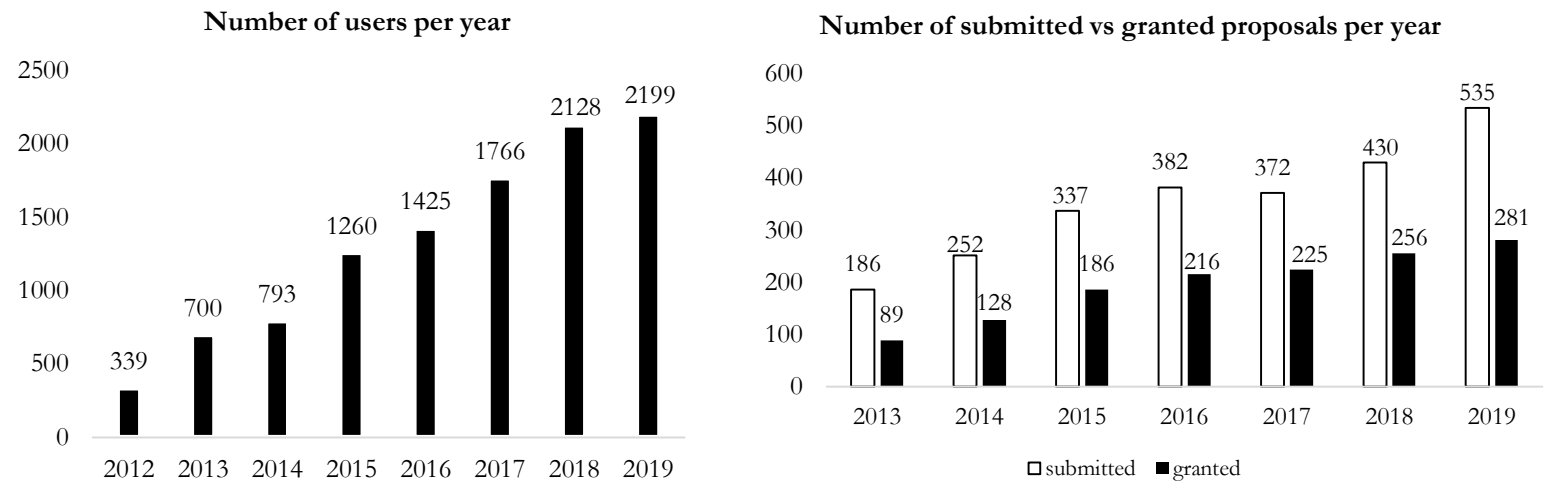

Source: Authors processing of ALBA data

Except for the very small share of beamtime allocated to proprietary research, the vast majority of experiments generate data, supporting publications in scholarly journals in different domains. At the time of drafting this paper, ALBA database includes a total of 1,723 publications ${ }^{14}$ of which $96 \%$ have been already published while $4 \%$ have been accepted for publication. The largest share $(71 \%)$ is published (or accepted for publication) in peer-reviewed journals or represents conference proceedings and book chapters (25\%) while a very small percentage (4\%) consists of a $\mathrm{PhD}$ thesis, technical notes or other (including patents). 1,109 publications (64\%) are actually related to the use of beamtime at ALBA, while 614 (36\%) are not beamtime related which means that they do not rely on experiments carried out at ALBA beamlines but are rather related to the construction and operation of the synchrotron. Most of these publications - especially the beamtime related ones - have been published from 2015 to 2019.

\footnotetext{
${ }^{14}$ ALBA data. Publications included in the database have been mostly published from 2000 onwards. Only 10 publications have been published in 1990s (specifically 1 in 1992, 7 in 1996 and 2 in 1998)
} 
Figure 2 An overview of ALBA publications by type and beamtime relation

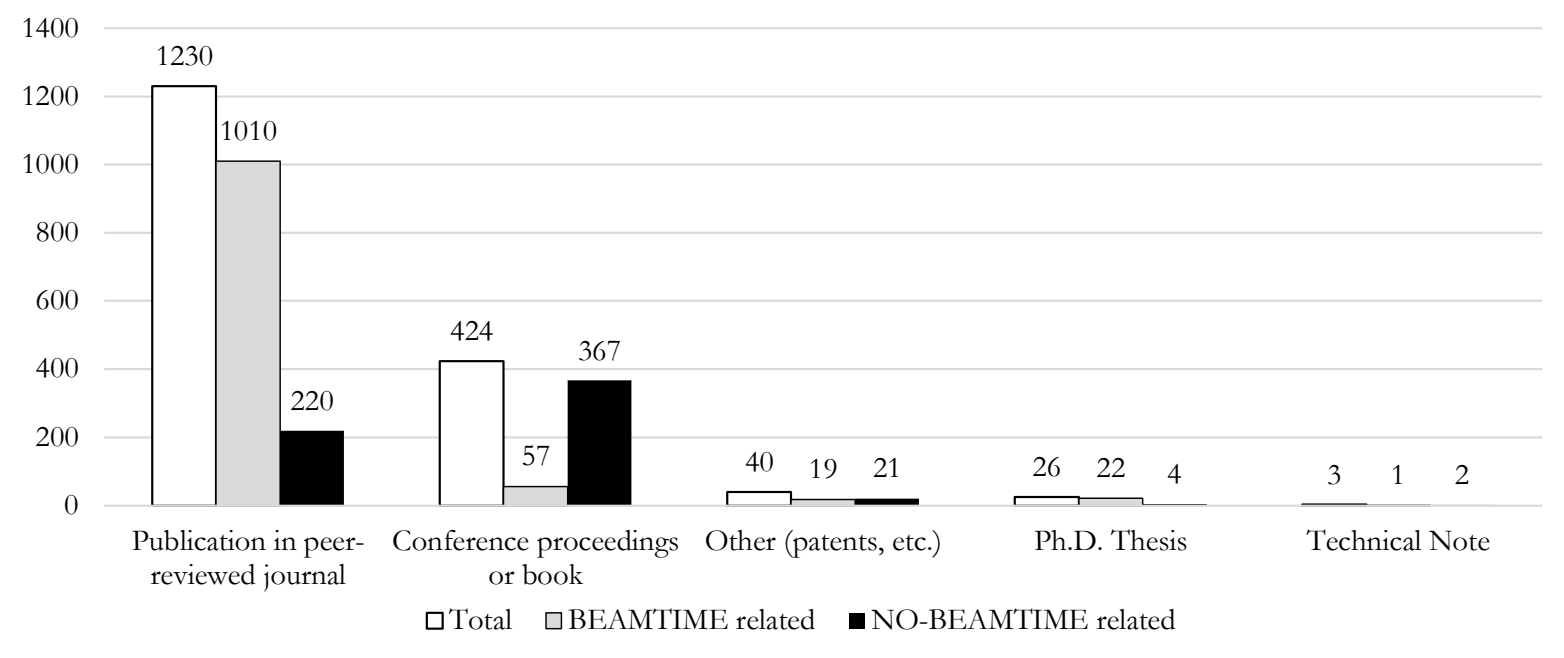

Source: Authors processing of ALBA data

The outcomes of ALBA experiments can be of interest for companies or applied researchers and can find applications in a wide and diverse range of fields, such as -to cite some examplespolymers (e.g., packaging), automotive, food, geo-science. This is confirmed by the declarations of around $10 \%^{15}$ of academic and researchers applying for beamtime at ALBA, between 2017 and 2019, which - during the application process - report about expected linkages between results of their experiments and industry soon after the experimental data are available, or after the publication of the results.

The objective of this paper is to investigate the linkage arising between the experiments and industry and specifically tracing and describing the pathways according to which innovation impacts materialise. In what follows, we provide more details on the methodology adopted as well as results achieved.

It is worth clarifying that ALBA is one of the many synchrotron light sources facilities which currently populate the international and EU RIs landscape. Similarly to ALBA, many other synchrotrons attract users from the scientific community and the private sector offering the possibility to perform in-depth studies with a precision that is not possible by other means. They tend to specialize on specific types of services. For instance, at CNAO in Pavia (Italy) or MedAustron in Wiener Neustadt (Austria), synchrotrons convey beams of protons or carbon-ions to a patient's solid cancer, when other forms of radiotherapy, based on photons, such as X-rays, are not appropriate and surgery is not an option. The direct users of such facilities are mainly researchers in radio-oncology and oncologists specializing in specific pathologies. Another example

\footnotetext{
${ }^{15}$ This information should, however, be taken with caution since it only reflects the perceptions of applicants while submitting the proposal.
} 
is the European Synchrotron Radiation Facility (ESRF) in Grenoble (France) which operates 44 beamlines (X-ray laboratories) and one cryo-electron microscopy laboratory. Each year, ESRF welcomes about 9,000 scientists which use its extremely brilliant X-rays for leading-edge research (mostly on energy materials) and industrial R\&D.

Currently, beamlines at ALBA are devoted mainly to biosciences, condensed matter (magnetic and electronic properties, nanoscience) and materials science.

There is a fierce competition amongst the wide array of available synchrotron light sources in attracting scientific and industrial users. However, as also demonstrated by results described in the following sections, users are fully aware of the technical capabilities offered by each synchrotron and they are completely free to apply for the one which satisfies the most their research needs.

\section{Methodological approach}

Florio (2019) argued that a possible strategy to evaluate the economic impact of the knowledge created by ALBA or similar synchrotron light sources could rely on the combination of two activities:

- Tracing the citations of the ALBA-related literature in filed patents;

- Launching a periodical survey of ALBA users to investigate whether they are aware of product or process innovations related to their experiments.

The combination of two methodologies allows using both objective and subjective evidence on the relation between the knowledge created thanks to the access to ALBA and a generated innovation output.

In order to collect evidence on perceptions, we designed two surveys ${ }^{16}$, one directed to ALBA beamline users and the other one to ALBA indirect users.

- The first survey targeted ALBA direct users (those accessing the facility physically or being part, even remotely, of the team carrying out the experiment). It represented a step forward with respect to the questionnaire addressed by ALBA to its users at the time of application, which only asks whether the experiment they are applying for has/is expected to have a connection with industry. Indeed, it was addressed to gather information on the pathways allowing for the generation of innovation impacts on the industry (if any), as per users' knowledge (e.g., by asking the type of innovation outputs arising from their experiments, the potential field of application, the time, the activities and resources needed for getting an innovation output stemming from results of experiments, etc.). Two

\footnotetext{
${ }^{16}$ See Catalano et al (2020) for detailed questionnaires.
} 
questionnaires were drafted for the launch of the first survey in order to take into account ALBA users from the scientific community (e.g., academic/researchers) and users from private companies. These questionnaires were fine-tuned through scoping interviews with selected users. The final versions were then uploaded on a web platform.

- The second survey targeted ALBA indirect users ${ }^{17}$ that are third parties (academics, companies, researchers, etc.) which have benefitted from results of the experiments carried out at ALBA by getting in contact with ALBA direct users or simply relying on their publications, but without accessing ALBA directly or being part of the experiment's design. The questionnaire for the second survey was designed to gather a more in-depth understanding of the innovation processes triggered by the experiments held at ALBA on third parties. Specifically, it investigated the innovation (e.g., of products, process, etc.) generated by these experiments, additional cost needed to achieve an innovation output by third parties, as well as potential economic impacts arisen (e.g., increase of turnover, entering in new markets, etc.).

Both surveys were launched on December 2nd, 2019 and run until March 30th, 2020. A management survey plan was adopted to solicit answers. Accordingly, reminders were periodically carried out by email and phone. Overall, 369 questionnaires were collected from the first survey (to direct users), and specifically 351 from the scientific community ${ }^{18}$ and 18 from the private sector ${ }^{19}$. The evidence collected from the second survey (overall 15 indirect users) were complemented with in-depth interviews and were used in our analysis to explain the pathways going from the results of the experiment to its spill over effects.

In addition to the two surveys, we performed an analysis on patents' citations, which uses bibliometric techniques to examine the wealth of patent citation information. Many studies have been relying on this analysis ${ }^{20}$ to assess the link between science and technology. Our analysis was specifically addressed to assess the extent to which innovations have been triggered by the knowledge produced by ALBA through publications. In other words, we looked at the extent to

\footnotetext{
${ }^{17}$ Since there is no tracking of the use of ALBA experiments' results by third parties, a major challenge was gathering email contacts for the launch of the survey. In this regard, two different solutions were designed: i) relying on the support of ALBA direct users by asking them to suggest contacts of third parties interested in the results of their experiments or forward the link to the second survey directly; ii) gathering contacts by identifying the authors of patents citing ALBA publications and thus indirectly benefitting from experiments carried out on beamlines.

${ }^{18}$ While accounting for $12 \%$ of the targeted users (2,947), these users represent 63\% of the proposals granted by ALBA from 2015 to 2019 (730 out of 1,164 proposals). This response rate suggests that this sample of respondents provides a good representation of the research activity carried out at ALBA during this period. Each respondent (either in the position of the main proposer, co-proposer or member of the team) has been involved in at least two granted proposals (the proportion between users and proposals presented is 2.08) and represents for each proposal a user team usually made up of 4-8 people. This sample is also representative of the geographical origin of ALBA users coming from the scientific community, the research fields covered by the proposals granted to them as well as their use of beamlines. See Catalano et al (2020) for more details.

${ }^{19}$ This sample accounts for $46 \%$ of ALBA users from this field (in total 39). It mirrors the size, the country of origin, the field of activities as well as the main beamlines used by private companies accessing ALBA. See Catalano et al (2020) for more details.

${ }^{20}$ See for instance: Yamashita, Y. (2018). Fukuzawa, N., \& Ida, T. (2016). Branstetter, L., \& Ogura, Y. (2005).
} 
which ALBA publications are cited in patent's documents and therefore contributed to the development of innovation outputs. For the purpose of this analysis, we considered the knowledge, directly and indirectly, generated by ALBA - such as publications directly produced by ALBA users - labelled as level 0 publications $\left(\mathrm{P}_{0}\right)$ - and publications citing ALBA users' publications - labelled as level 1 publications $\left(\mathrm{P}_{1}\right)$.

This analysis required the following actions:

a. Analysis of ALBA publications database, namely $\left(\mathrm{P}_{0}\right)$ publications;

b. Extraction of scientific publications which cite ALBA publications, namely $\left(\mathrm{P}_{1}\right)$ publications, from relevant publicly available repositories of scientific publications (Lens PatCite $)^{21}$

c. Creation of an ad-hoc database including bibliographic data - such as titles, authors, coauthors, affiliations and country, abstracts, doi, year of publication, journal of publications, etc. - of $\left(\mathrm{P}_{0}\right)$ and $\left(\mathrm{P}_{1}\right)$ publications.

d. Identification of patents $\left(\mathrm{Pat}_{0}\right)$ citing ALBA publications $\left(\mathrm{P}_{0}\right)$ as well as those patents $\left(\mathrm{Pat}_{1}\right)$ citing publications $\left(\mathrm{P}_{1}\right)$ which in turn cite ALBA publications $\left(\mathrm{P}_{0}\right)$.

To perform the above actions, and in line with available literature on database for bibliometric and scientometric analyses ${ }^{22}$, we created a relational database ${ }^{23}$ which allowed us to link different tables amongst which one-to many relationships were found (e.g., one publication in a dataset was associated to many patents in other datasets provided by Lens PatCite). Results were then processed and visualised through the use of graphs. Our analysis goes beyond the monitoring activity currently performed by ALBA, which is limited to track the publications arising from experiments. Indeed, it allowed:

- Getting the number of patents which have been developed starting from ALBA's $\left(\mathrm{P}_{0}\right)$ and $\left(\mathrm{P}_{1}\right)$ publications;

- Mapping the field/sector of applications in which these innovations have been developed;

- Identifying publications with technological importance and information on their topic, authors, co-authors involved.

\footnotetext{
${ }^{21}$ https://www.lens.org/. Lens is the world's largest open and free data platform of the global patents and scholarly articles.

${ }^{22}$ See for instance: Batra, S., \& Tyagi, C. (2012), Ginde, G., et al (2018), Medhi, S., \& Baruah, H. K. (2017), Mallig, N. (2010), Fernández, M. T., et al (1993).

${ }^{23}$ The choice to use a relational database for this analysis was related to the limited number of data and tables connected. We considered the use of a graph database (storing the data in the form of nodes and arcs) for a social network analysis of LEAPS publications and related citations, of which ALBA is part, to be eventually carried out in the future. In this case, the use of a graph database would be more suitable since data are massive in scale and there would be a large number of joining tables. In this case, the graph database (e.g., by using Neo4j, a type of NoSQL database) would facilitate the analysis of the collaboration networks, semantic networks and publication citation networks arisen within LEAPS.
} 
- Describing the time gestation lag of these innovations, such as the time lag that separates the year of the publication and the year of patent's registration.

The evidence collected through the two surveys, in-depth interviews and analysis of patent citations allowed us to trace and describe the pathways from the design of the experiments to the innovation outputs, as presented in the following section.

\section{Results}

The evidence collected will be presented in this section by distinguishing between three main phases featuring the pathways to innovation, such as: a) from the design to the execution of the experiment; b) from the execution of the experiment to the innovation output; c) from the experiment's results to its spill over effects.

\subsection{From the design to the execution of the experiment}

Experiments carried out at ALBA synchrotron are rarely designed by scientific and industrial communities jointly. Survey's results show that users from the scientific community usually carry out their experiment alone or mostly in collaboration with other universities/research centres (see Table 2.a). Similarly, private companies usually perform their experiment alone $(54.8 \%$ of experiments) or in collaboration with other private companies $(36.4 \%)$.

No specific strategy is adopted to engage industrial collaborations since the design of the experiments, although respondents to the survey recognise that results from their experiments may have a potential application for industry. Users from the scientific community limit their strategy to publishing in peer-reviewed journals or attending conferences (Table 2.b). This is because it is mostly unsuitable for an immediate industrial application and therefore less attractive for industrial partnership. Interviews suggest that networking with private companies works well if properly supported by technology transfer units or university spin-offs, i.e. bodies or entities used to play a liaising role between academia and industry.

Experiments require skills and expertise to operate the beamlines as well as to interpret and understand the results. The evidence collected confirm that users from the scientific community are usually experts who boast these skills and self-operate the beamlines themselves or in collaboration with ALBA staff while users from the private sector mostly rely on ALBA support (Table 2.c). Both users from the scientific community and private sector may act as 'intermediary' performing the experiment on behalf of third parties which specifically need the experiment for the purpose of their research. 


\section{Table 2 The design and execution of the experiments at ALBA}

\section{2.a Type of collaboration during the design phase}

Question: "On the total of experiments carried out at ALBA, please indicate the share of those for which the application was submitted by"

$\mathrm{N}^{\circ}$ of respondents: 351 from the scientific community and 18 from the private field.

\begin{tabular}{rccc}
\hline & $\begin{array}{c}\text { Average share of experiments carried out } \\
\text { by Scientific Community }\end{array}$ & $\begin{array}{c}\text { Average share of experiments carried out } \\
\text { by Private Sector }\end{array}$ & 54.82 \\
\hline In collaboration with other universities/research institutes & 53.22 & 4.12 \\
\hline $\begin{array}{r}\text { In collaboration with both private companies and other } \\
\text { universities/research institutes }\end{array}$ & 43.26 & 2.54 \\
\hline In collaboration with private companies & 0.98 & 36.35 \\
\hline TOTAL & $\mathbf{1 0 0}$
\end{tabular}

2.b Type of collaboration during the design phase

Question: “What is your strategy (if any) to involve companies in your experiments/exploitation of results of your experiments at synchrotron light sources"

$\mathrm{N}^{\circ}$ of respondents: 351 from the scientific community. This question was not asked to users from private sector.

\begin{tabular}{rc}
\hline & Number of survey's respondents (multiple answers allowed) \\
\hline $\begin{array}{r}\text { Publishing in journals of interest for companies or other } \\
\text { players interested in potentially technological developments }\end{array}$ & 142 \\
\hline $\begin{array}{r}\text { No strategy since not interested in the industrial applications } \\
\text { of results of their experiments }\end{array}$ & 128 \\
\hline $\begin{array}{r}\text { Joining conferences and/or other events attended by } \\
\text { companies or other players interested in potentially } \\
\text { technological developments } \\
\text { the results of my experiments }\end{array}$ & 63 \\
\hline Oelying on a network of companies and inform them about & 14
\end{tabular}

\section{2.c Performance of the experiment}

Question: "On the total of experiments carried out at ALBA, please indicate the share of those carried out by"

$\mathrm{N}^{\circ}$ of respondents: 351 from the scientific community and 18 from the private field.

\begin{tabular}{rrr}
\hline & $\begin{array}{c}\text { Average share of experiments carried } \\
\text { out by Scientific Community }\end{array}$ & $\begin{array}{c}\text { Average share of experiments carried } \\
\text { out by Private Sector }\end{array}$ \\
\hline By self-operating the beamline & 31.23 & 14.72 \\
\hline By relying on ALBA staff & 20.55 & 65.56 \\
\hline A mix of both & 48.22 & 19.72 \\
\hline TOTAL & $\mathbf{1 0 0}$ & Source: Authors processing of surveys data
\end{tabular}

Note: * It includes: occasional contacts with companies, no strategy at the moment but this may be eventually adopted in the

The majority of respondents from the private field (44\%) carries out their experiments with the objective to use results internally; $28 \%$ acts as intermediate service companies (these are companies dealing with research and experimental development on chemicals and pharmaceuticals or other professionals, scientific and technical activities); the remaining $20 \%$ use the results either for an internal or external purpose (Figure 3.a).

On average, $52 \%$ of experiments are designed and carried out by users from the scientific community as part of a broader research project while $48 \%$ as a self-standing activity providing an answer to a specific research question or need from indirect users. The survey's responses confirmed that the use of ALBA beamlines is usually related to a specific type of research (basic 
research, applied research or industrially relevant, Figure 3.d) as well as to a research fields/sector of activity (Figure 3.b).

Figure 3 The rationale behind the experiments

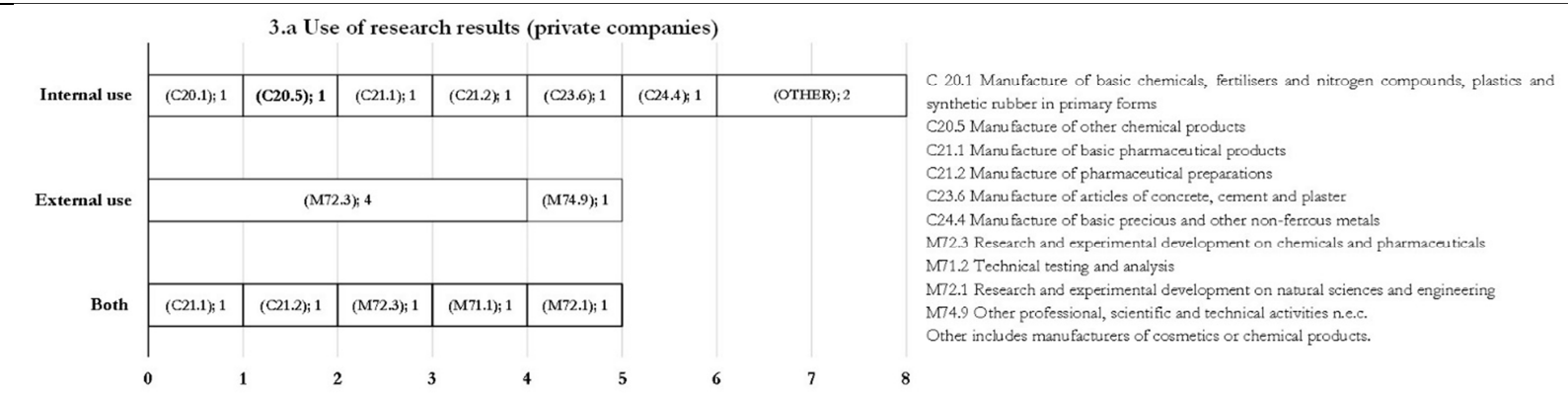

Note: Number of survey's respondents. Question: "For which purpose, are the results - obtained from experiments at ALBA - used for" by sector of activity of the respondent. $\mathrm{N}^{\circ}$ of respondents: 18 from the private field.

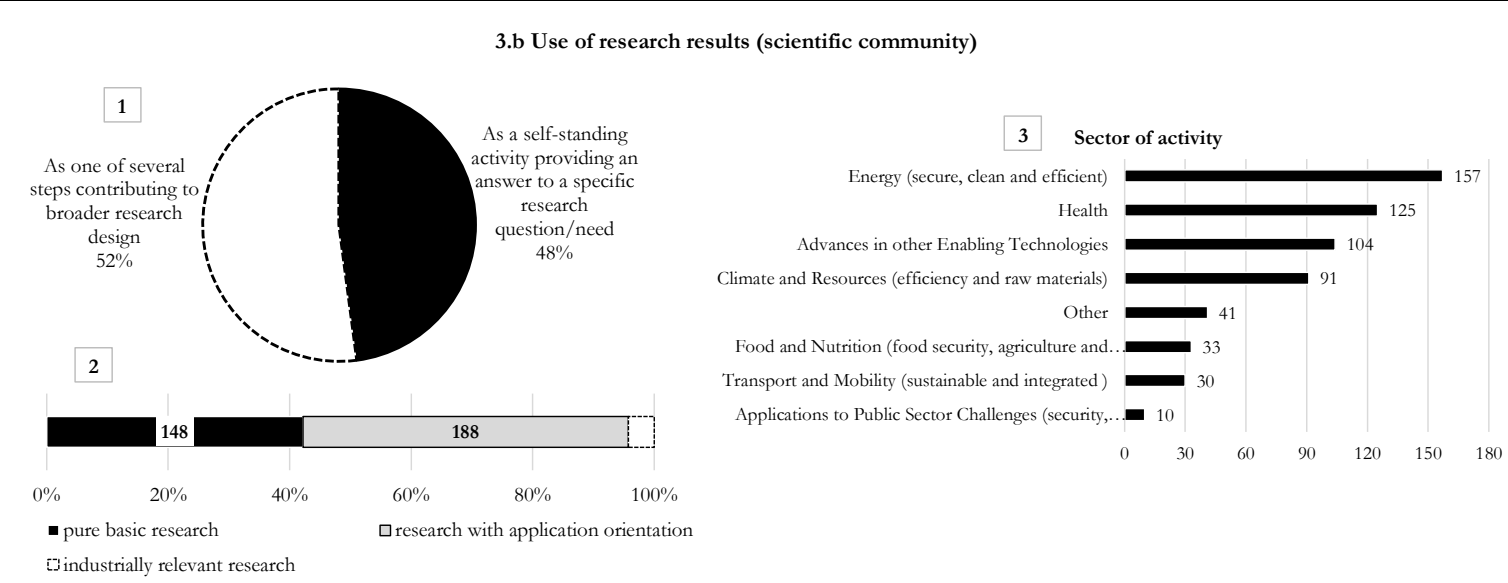

Note: 1) and 2) Average share of experiments carried out by survey's respondents; 3) number of respondents (multiple answers allowed)

Question: 1) "On the total of your experiments at ALBA, please indicate the share of those carried out" ;2) "On the total of your experiments at ALBA, please indicate the share of those whose results are useful for" . 3) "In which potential area of application may your research eventually

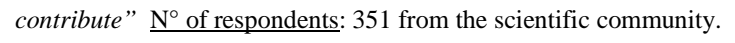

Source: Authors processing of surveys data

Interestingly, the choice to use ALBA beamlines is related to specific needs which could not have been met by other synchrotrons. A relatively high share of respondents reported that they could not have performed their research without the specific beamlines provided by ALBA (42\% of respondents) and that using other alternatives (e.g., other synchrotrons or equipment/technologies) would have required longer time (43\%) and entailed higher costs (45\%).

\subsection{From the execution of the experiment to the innovation output}

Once the experiment is completed, it is infrequent that the results are immediately used. The survey to users of ALBA showed that, in most cases, the experiment represents a step contributing to broader research, and therefore, it requires additional time and complementary research activities to create innovation with economic relevance. 
According to respondents from the scientific community, most of the experiments (40\%) need additional research activities carried out at their institutions, followed by a relatively low percentage of experiments which need additional activities carried out by specialised companies (25\%) or in other synchrotrons/research institutes $(22 \%)$. When the experiment is carried out by users from private company, additional activities carried out internally are mostly needed (50\% of experiments) followed by those (on average, $21.7 \%$ of experiments carried out) which need additional activities carried out by specialised companies. Only for a small share (13\%), additional researches in other research institutes or synchrotrons are needed (see Table 3).

\section{Table 3 Additional research activities needed to develop innovation}

\begin{tabular}{|c|c|c|}
\hline \multicolumn{3}{|c|}{$\begin{array}{l}\text { Question: "Considering the results of all your experiments at ALBA, please indicate the share of those for which the following steps/additional } \\
\text { activities are usually needed to create an innovation output" } \mathrm{N}^{\circ} \text { of respondents: } 333 \text { from the scientific community and } 18 \text { from the private users.. }\end{array}$} \\
\hline & $\begin{array}{l}\text { Average share of experiments carried out } \\
\text { by Scientific Community }\end{array}$ & $\begin{array}{l}\text { Average share of experiments carried out } \\
\text { by Private Sector }\end{array}$ \\
\hline $\begin{array}{r}\text { Additional research activities carried out internally are } \\
\text { needed to create an innovation output }\end{array}$ & 39.85 & 50.00 \\
\hline $\begin{array}{r}\text { Additional research activities carried out by specialised } \\
\text { companies are needed to create an innovation output }\end{array}$ & 25.38 & 21.66 \\
\hline $\begin{array}{r}\text { Additional research activities in other research institutes } \\
\text { and/or synchrotrons are needed to create an innovation } \\
\text { output }\end{array}$ & 22.35 & 12.78 \\
\hline $\begin{array}{l}\text { They can be immediately used for innovation purposes } \\
\text { and do not need additional research activities or testing }\end{array}$ & 6.79 & 15.56 \\
\hline Other & 5.63 & - \\
\hline TOTAL & 100 & 100 \\
\hline
\end{tabular}

Both users from private companies and scientific community show uncertainty about the time needed to develop an innovation output - with economic or practical significance - on the basis of their experiments at ALBA. Specifically, 47\% of respondents from the scientific community declares that they are not aware of the timing needed to translate their research results into innovation; $2 \%$ suggests that it may take less than 1 year while a significant share of respondents (about $35 \%$ ) states that from 1 to 5 years are possibly needed. The remaining $16 \%$ suggests that more than 5 years may be needed. Similarly, there is a high share of respondents $(44 \%)$ from the private field which has no idea of the time from research to innovation; $11 \%$ suggests that it may take less than 1 year while overall 34\% suggests that the timing may range from 1 to 5 years. The remaining percentage (11\%), suggests that from 6 to 8 years are possibly needed.

Overall, the evidence collected shows that the time and the activities needed to achieve innovation outputs vary depending on the type of research carried out, the research field/sector of activity of the user as well as the beamlines used. When the experiment is carried out by users from the scientific community, not surprisingly, the pathways to innovations are longer in the case of experiments entailing pure basic research while a shorter time frame is suggested for research with application orientation or industrially relevant research (Figure 4.a). The pathways to innovations 
are faster in the case of research with application orientation or industrially relevant research in the field of chemistry, material science for energy/information technology, biology-life sciences and protein crystallography (from 1 to 5 years). A longer time may be required for experiments in the field of solid-state physics and materials science concerning structure, phase transitions, nanomaterials as well as in the field of instrumentation and techniques development (Figure 4.b). The survey also showed that there are some beamlines - such as BL04-MSPD, BL22-CLAESS, BL13-XALOC, BL01-MIRAS and BL011-NCD-SWEET - which are 'faster' to innovation since they are related mostly to a type of research oriented to application and covering specific research fields.

Even when the user is from the private field, the time to create the innovation depends on the sector of activity of the user. If the experiments are carried out by a manufacturer (e.g., of pharmaceutical preparations as well as of concrete, cement and plaster articles or basic precious and other non-ferrous metals), 1-2 years may be needed to develop a new product or to improve an existing one. Instead, a longer time is required where the experiment is carried out by companies carrying out research which most likely operate on behalf of indirect users (Figure 4.c). These include companies dealing with research and experimental development on chemicals and pharmaceuticals, manufacture of chemical products or basic pharmaceutical product, technical testing and analysis. Looking more in detail to the answers provided by these respondents, it arises that experiments carried out by these users may contribute to the initial phases of innovation development but, then, additional time is needed to carry out research mostly internally but also at other synchrotrons/research institutes or by specialised companies. In the field of basic pharmaceutical products, one user suggests that the development of innovation can also take from 6 to 8 years. In addition to the time, the amount of resources needed to develop innovation can also vary a lot within the same sector. For instance, respondents indicate that experiments from companies dealing with basic pharmaceutical products may require less than EUR 500,000 to develop an innovation - entailing the cost of 1-5 people and of accessing to additional synchrotrons - or also up to 1 billion - entailing the cost of 6-10 people as well as of raw materials and/or instruments for carrying out additional research or of services by specialised companies. 


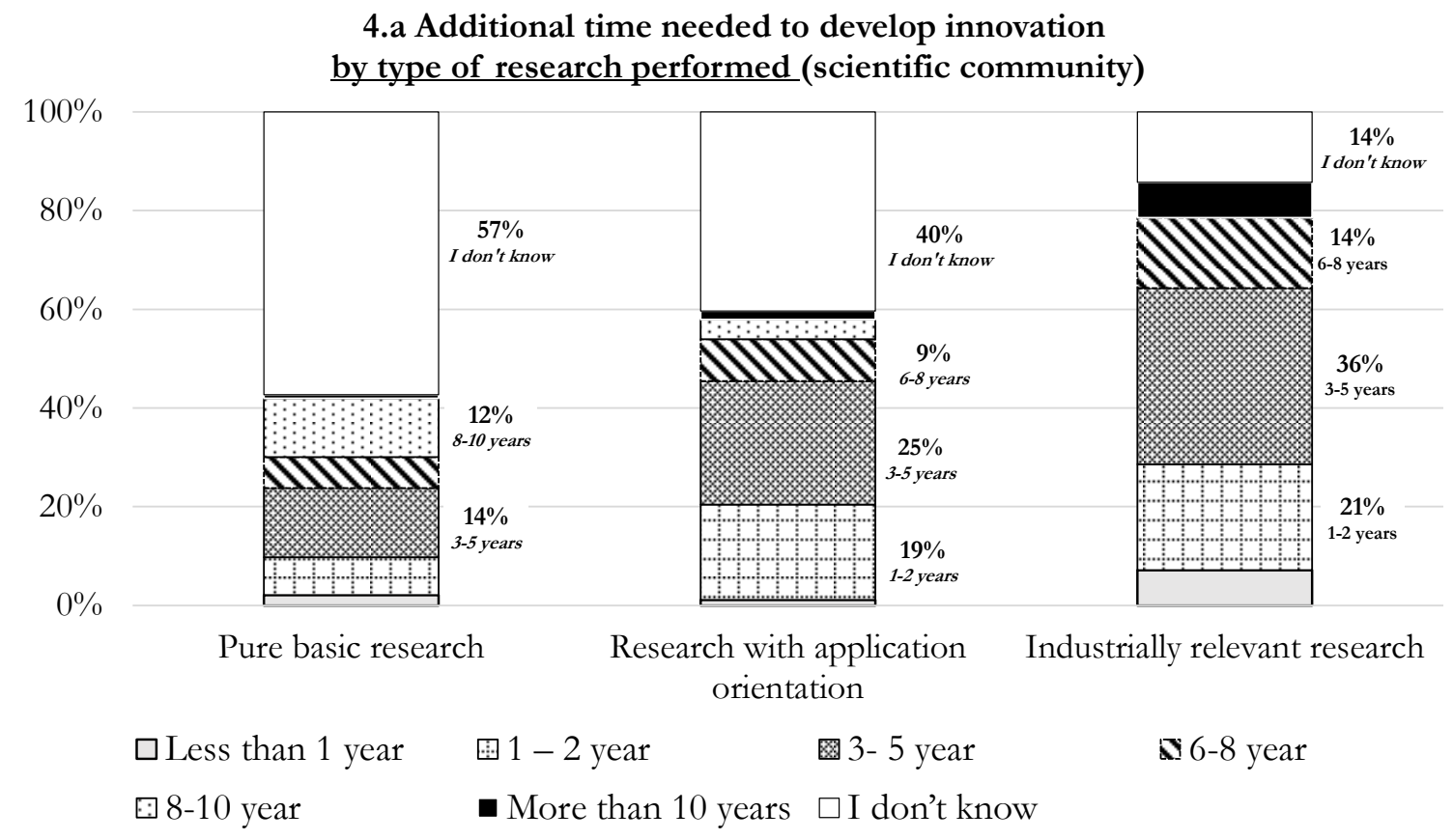

Note: Share of survey's respondents by type of research and years needed to create an innovation output. Question: "On average, stemming from the results of your experiments at ALBA how much additional time it would take to develop innovation with economic or practical significance" $\mathrm{N}^{\circ}$ of respondents: 333 from the scientific community.

4.b Additional time needed to develop innovation by field of research (scientific community)

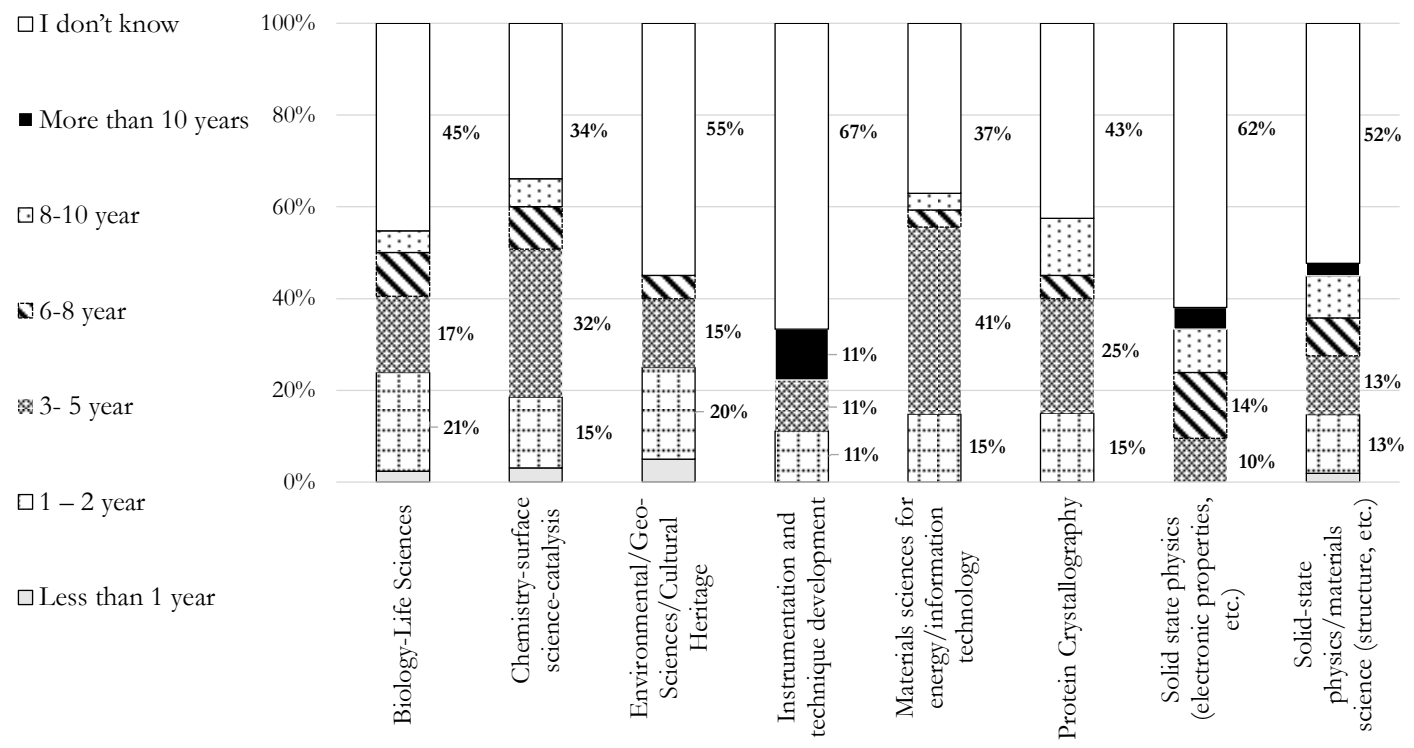

Note: Share of survey's respondents by field of research and years needed to create an innovation output. Question: "On average, stemming from the results of your experiments at ALBA how much additional time it would take to develop innovation with economic or practical significance" $\underline{\mathrm{N}^{\circ} \text { of respondents: }} 333$ from the scientific community. 
4.c Time needed by type of research and sectors of activity (private field)

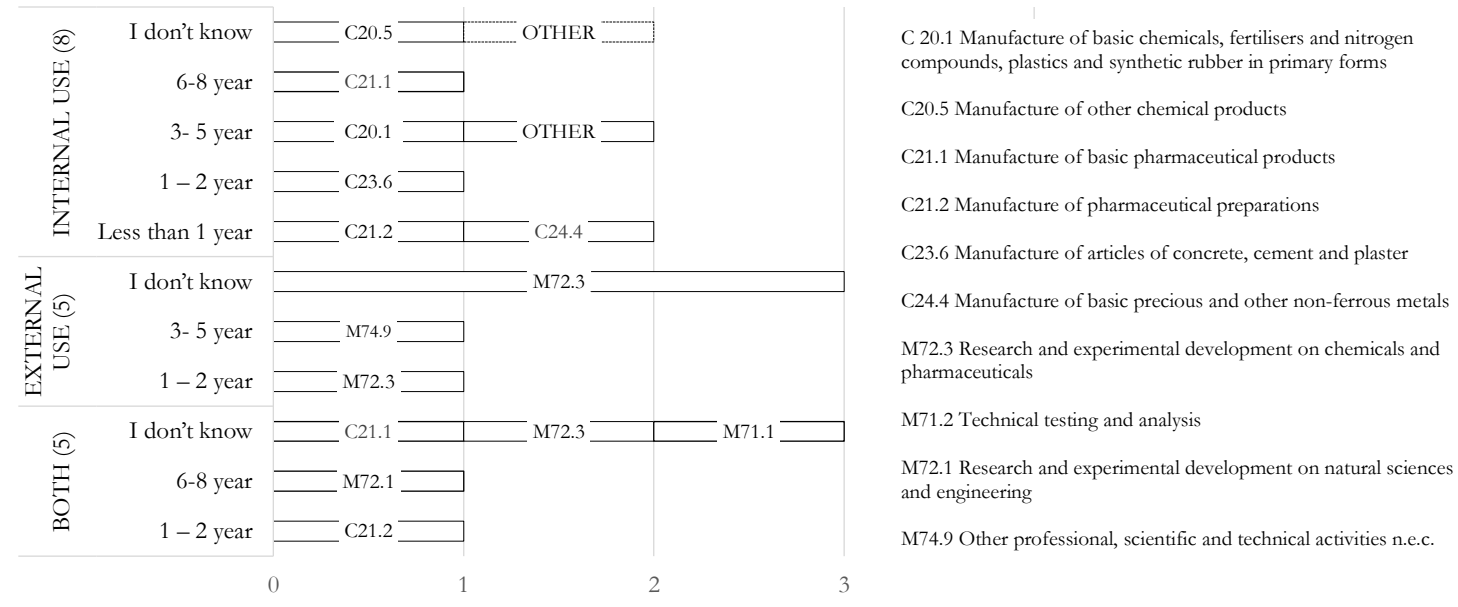

Note: Number of respondents by type of research, sectors of activity, years needed to develop innovation Question: "On average, stemming from the results of your experiments at ALBA how much additional time it would take to develop innovation with economic or practical significance" $\mathrm{N}^{\circ}$ of respondents: 18 from private users.

Source: Authors processing of surveys data

\subsection{From the experiment's results to its spill over effects}

According to the evidence collected with the survey, the knowledge gathered by the scientific community through the experiments carried out at ALBA always (48\% of respondents) or very often $(39 \%)$ translates into publications while very rarely immediately into patents or other intellectual property (see Table 4). This evidence further confirms the findings presented in the previous sections that results are mostly used by the scientific community to advance in research (e.g. by getting a better understanding of their research and/or improving the quality of analysis) and enhance the knowledge in a specific field or in relation to a certain topic while additional time and activities are needed - starting from the performance of the experiments - to develop an innovation of economic relevance.

\section{Table 4 Outputs of the experiments by the scientific community}

\begin{tabular}{|c|c|c|c|c|c|c|}
\hline \multicolumn{7}{|c|}{$\begin{array}{l}\text { Question: "How frequently did results of your experiments translate into" Share of respondents. } \\
\mathrm{N}^{\circ} \text { of respondents: } 351 \text { from the scientific community. }\end{array}$} \\
\hline & $\begin{array}{r}\text { Never } \\
(0 \%)\end{array}$ & $\begin{array}{c}\text { Rarely } \\
\text { (less than } 30 \% \\
\text { of cases) }\end{array}$ & $\begin{array}{c}\text { Sometimes } \\
(30 \%-50 \% \text { of } \\
\text { cases })\end{array}$ & $\begin{array}{l}\text { Very often }(50 \% \\
\text { - less than } 100 \% \\
\text { of cases) }\end{array}$ & $\begin{array}{l}\text { Always } \\
(100 \% \text { of cases })\end{array}$ & Total \\
\hline Patents & 64.7 & 29.9 & 4.0 & 0.9 & 0.6 & 100.0 \\
\hline Publication in peer-reviewed journal & 4.6 & 1.7 & 6.0 & 39.3 & 48.4 & 100.0 \\
\hline Conference proceedings or book & 13.1 & 17.7 & 19.7 & 30.5 & 19.1 & 100.0 \\
\hline Ph.D. Thesis & 10.8 & 5.1 & 18.2 & 36.2 & 29.6 & 100.0 \\
\hline Technical Note & 61.3 & 23.6 & 10.0 & 3.1 & 2.0 & 100.0 \\
\hline
\end{tabular}


However, both respondents from the scientific community and private field recognise that as a result of the new knowledge generated by their experiments on ALBA beamline, companies and other players interested in technological developments were able/could be able in the future to develop new technologies and new products, to improve technical know-how, R\&D and innovation capabilities and quality of existing products while the development of new patents, copyrights, or other intellectual property rights ranks lower in their list (see Figure 5). Where developed directly by ALBA users, patents have mostly concerned the following sectors: chemistry, nanotechnology, energy and pharmaceutical.

\section{Figure 5 Innovation outputs achieved thanks to experiments carried out at ALBA}

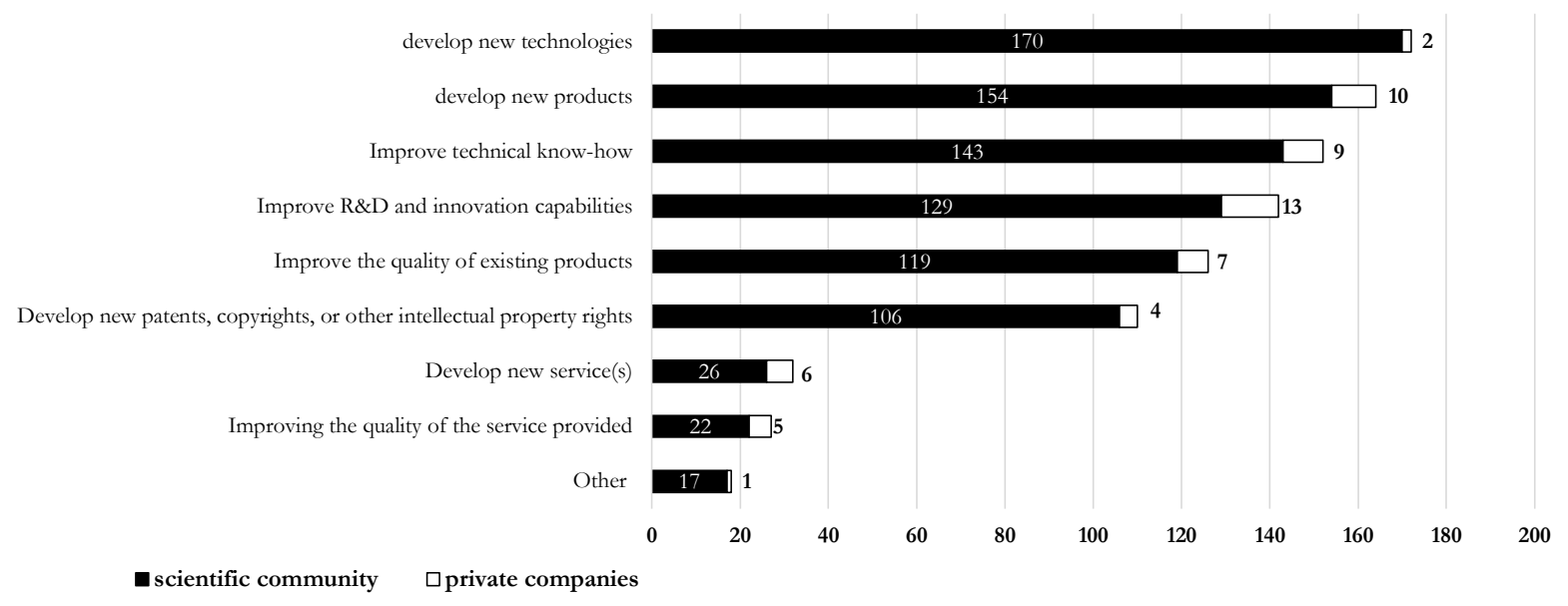

Note: Number of respondents. Multiple answers were allowed. Question: "From your knowledge, what is (or could be in the future) the innovation output achieved thanks to the experiments carried out at ALBA beamlines" $\mathrm{N}^{\circ}$ of respondents: 351 from the scientific community and 18 from the private users.

Source: Authors processing of surveys data

In this regard, the evidence collected from survey to indirect users (the second survey, overall 15 answers) confirmed that results from experiments carried out at ALBA - even when embedded in publications - have been used as one of the several 'ingredients' to advance in their research and that they have contributed to different sectors, although the most cited ones are energy, food and nutrition, health, biodegradable packaging materials, climate and resources. For instance, results have been used for improving the design of materials for food-related applications, for understanding the structure of polysaccharides (e.g. cellulose, agar, carrageenan, etc.) in biodegradable packaging materials or in gels developed for food ingredients, for advancing with the diagnosis of Parkison's Disease, to understand active protein crystals grown in-situ within the hydrogel allowing to manufacture pharmaceutical compositions, etc.

The knowledge and improvements (e.g. to their product/services, etc.) gained with the experiments on ALBA beamlines are likely to generate economic benefits in the private sector. As 
recognised by the private users answering the survey (18 respondents to the first survey and accounting for $46 \%$ of users from the private field), as a consequence of the knowledge acquired with experiments, they were able to be more competitive for clients ( $72 \%$ of respondents), to increase their total sales to customers $(44 \%)$, their overall profitability $(50 \%)$ as well to get new customers $(50 \%)$. Amongst these respondents, there are companies operating in the fields of manufacture of basic pharmaceutical products, manufacture of pharmaceutical preparations, manufacture of articles of concrete, cement and plaster, research and experimental development on chemicals and pharmaceuticals and technical testing and analysis.

\section{Table 5 Economic impacts}

\begin{tabular}{|c|c|c|c|c|c|c|c|}
\hline \multicolumn{8}{|c|}{$\begin{array}{l}\text { Question: "Please, indicate your level of ag } \\
\text { product/services, etc.) gained with the experin } \\
\mathrm{N}^{\circ} \text { of respondents: } 18 \text { from the private users. }\end{array}$} \\
\hline & Disagree & Neutral & Agree & Strongly agree & I don't know & Not applicable & Total \\
\hline $\begin{array}{r}\text { Increased total sales to } \\
\text { customers }\end{array}$ & 5.6 & 16.7 & 38.9 & 5.6 & 5.6 & 27.8 & 100.0 \\
\hline $\begin{array}{r}\text { Being more } \\
\text { competitive for clients }\end{array}$ & 5.6 & 5.6 & 27.8 & 44.4 & 0.0 & 16.7 & 100.0 \\
\hline $\begin{array}{r}\text { Increased overall } \\
\text { profitability }\end{array}$ & 5.6 & 11.1 & 38.9 & 11.1 & 16.7 & 16.7 & 100.0 \\
\hline Get new customers & 11.1 & 22.2 & 27.8 & 22.2 & 0.0 & 16.7 & 100.0 \\
\hline
\end{tabular}

Interestingly, while the surveys' results suggest that the knowledge created at ALBA often translates in publications and rarely in patents, the analysis of patents' citations showed that the knowledge embodied in ALBA scientific publications has contributed to develop patents. Our analysis found that 21 out of 1,723 publications generated by ALBA users (P0 publications) had been cited for developing 35 patent documents of level 0 (Pat0). More indirectly, 243 out of 9,974 publications citing ALBA publication (P1 publications) have contributed to developing 337 patent documents of level 1 (Pat1).

\section{Figure 6 - Results from patents' analysis}

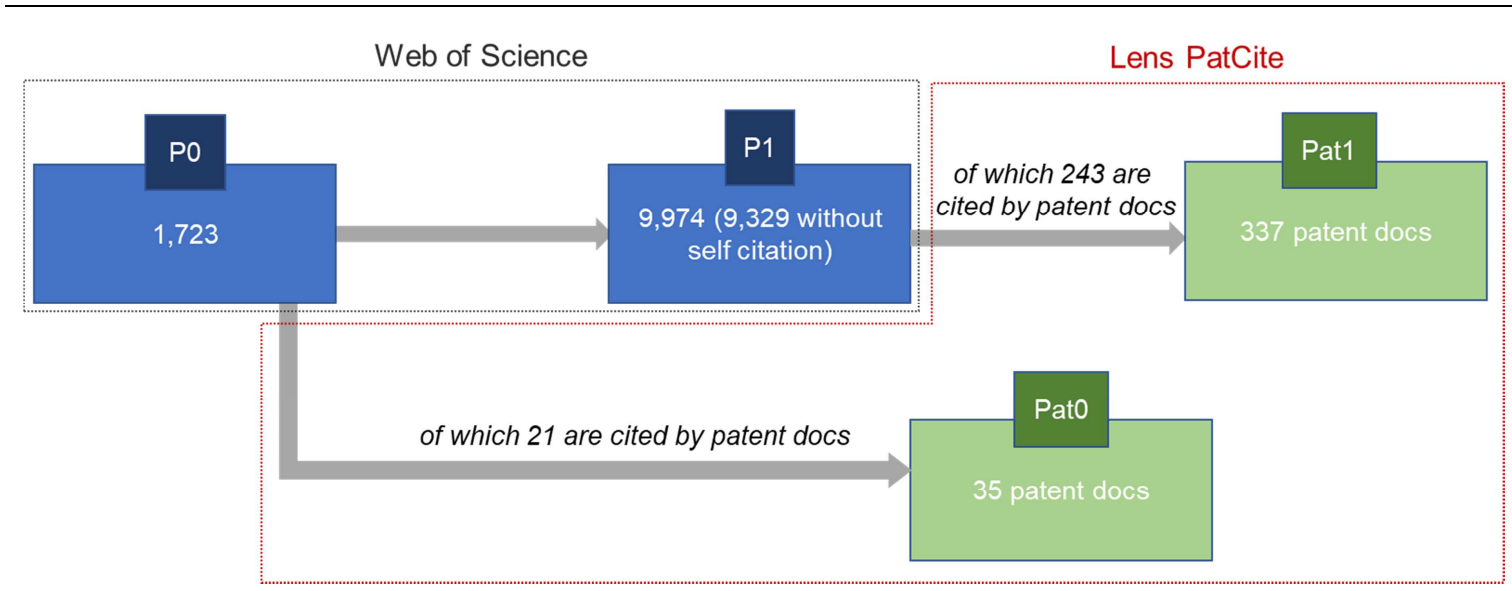


Focusing on ALBA P0 publications, we found that:

- All cited articles are in the field of chemistry, involve several authors (from a minimum of 3 up to 18) and were published in the period 2013-2019 with the exception of one article which dates back to 2005 (Table 6).

- 16 out of 21 publications are actually related to the use of beamtime at ALBA, while 5 are not beamtime related (Table 6 ).

- At the time of the application process for ALBA beamtime, none of the articles was associated with industrial relevance/collaboration/involvement with the exception of one article for which collaboration with an industrial group was indicated (Table 6). Nevertheless, 16 out of 35 patent documents (46\%) which cite these articles are owned by a firm or by a firm in partnership with a university or a public research institute. This fact reveals that such publications were to some extent of interest for industry.

- Most of the patent documents are owned by a sole entity (65\%) either a firm (25\%), a university $(23 \%)$ or a public institute $(17 \%)$ thus confirming the finding of the survey about a limited collaboration between the scientific community and private sectors in designing experiments at ALBA as well as developing patents on the basis of their results.

- The highest number of P0 publications has been generated from experiments carried out at XALOC (BL13, see green circle in Figure 7 below), while MSPD (BL04, see the yellow circle in Figure 7) is the beamline associated to the higher number of patent documents (10 out of 27).

- 19 out of 35 patent documents report more than one technological area of application (Figure 7 below). $51 \%$ of patent documents pertain to some extent to the field of chemistry metallurgy while the two technological areas most frequently reported in the documents are "H01 - Basic Electric Elements" and "A61 - Medical or Veterinary Science Hygiene”.

- The number of patent citations per article range from 1 to 6 . The most cited article titled "Na3V2(PO4)2F3 Revisited: A High-Resolution Diffraction Study" which has been cited by 6 patent documents corresponding to 5 different patent families (Table 6 and black circle in Figure 7). Only in two cases, the same patent document cites more than one publication of level 0 (red circles in Figure 7).

Table 6 and Figure 7 summarise the main findings of our analysis. 
Table 6 Level 0 publications cited by patent documents

\begin{tabular}{|c|c|c|c|c|c|c|c|c|c|}
\hline YEAR & TITLE & $\begin{array}{c}\mathrm{N}^{\circ} \text { OF } \\
\text { AUTHORS }\end{array}$ & \begin{tabular}{|c} 
AUTHORS \\
FROM \\
ALBA
\end{tabular} & ALBA BEAM & $\begin{array}{l}\text { TYPE OF } \\
\text { RESEARCH }\end{array}$ & $\begin{array}{l}\text { INDUSTRIAL } \\
\text { RELEVANT }\end{array}$ & $\begin{array}{l}\text { COLLABOR. } \\
\text { WITH AN } \\
\text { INDUSTRIAL } \\
\text { GROUP }\end{array}$ & $\begin{array}{l}\text { INDUSTRIAL } \\
\text { INVOLVEMENT }\end{array}$ & $\begin{array}{c}\text { CITING } \\
\text { PATENTS } \\
\text { (FAMILIES) }\end{array}$ \\
\hline 2014 & Na3V2(PO4)2F3 Revisited: A High-Resolution Diffraction Study & 8 & Yes & MSPD (BL04) & In-house & No & No & No & $6(5)$ \\
\hline 2016 & $\begin{array}{l}\text { Poly (alkylene } 2,5 \text {-furandicarboxylate)s (PEF and PBF) by ring opening } \\
\text { polymerization }\end{array}$ & 3 & No & $\begin{array}{l}\text { NCD-SWEET } \\
\text { (BL11) }\end{array}$ & Academic & No & No & No & $4(4)$ \\
\hline 2013 & $\begin{array}{l}\begin{array}{l}\text { Exceptional oxidation activity with size-controlled supported gold } \\
\text { clusters of low atomicity }\end{array} \\
\end{array}$ & 13 & Yes & $\begin{array}{l}\text { CLAESS } \\
\text { (BL22) }\end{array}$ & Friendly & No & No & No & $3(3)$ \\
\hline 2015 & $\begin{array}{l}\text { Metal organic framework-mediated synthesis of highly active and stable } \\
\text { Fischer-Tropsch catalysts }\end{array}$ & 18 & No & $\begin{array}{l}\text { CLAESS } \\
\text { (BL22) }\end{array}$ & Academic & No & No & No & $2(2)$ \\
\hline 2015 & $\begin{array}{l}\text { Faceted phospholipid vesicles tailored for the delivery of Santolina } \\
\text { insularis essential oil to the skin }\end{array}$ & 13 & No & $\begin{array}{c}\text { NCD-SWEET } \\
\text { (BL11) }\end{array}$ & Academic & No & No & No & $2(1)$ \\
\hline 2018 & $\begin{array}{l}\text { Potential of lignocellulosic fractions from Posidonia oceanica to improve } \\
\text { barrier and mechanical properties of bio-based packaging materials }\end{array}$ & 3 & No & $\begin{array}{c}\text { NCD-SWEET } \\
(\text { BL11) }\end{array}$ & Academic & No & No & No & $2(1)$ \\
\hline 2015 & $\begin{array}{l}\begin{array}{l}\text { Effect of calcium sulfate source on the hydration of calcium } \\
\text { sulfoaluminate eco-cement }\end{array} \\
\end{array}$ & 6 & No & No beamtime & $\begin{array}{c}\text { No } \\
\text { beamtime }\end{array}$ & No & No & No & $2(1)$ \\
\hline 2015 & $\begin{array}{l}\text { Comprehensive Investigation of the Na3V2(PO4)2F3-NaV2(PO4)2F3 } \\
\text { System by Operando High Resolution Synchrotron X-ray Diffraction }\end{array}$ & 7 & Yes & MSPD (BL04) & Academic & No & No & No & $2(2)$ \\
\hline 2014 & $\begin{array}{l}\text { Structural insight into the molecular mechanism of allosteric activation of } \\
\text { human cystathionine } \beta \text {-synthase by S-adenosylmethionine }\end{array}$ & 5 & No & XALOC (BL13) & Academic & No & Yes & No & $2(2)$ \\
\hline 2017 & $\begin{array}{l}\text { Characterization of highly crystalline lead iodide nanosheets prepared by } \\
\text { room-temperature solution processing }\end{array}$ & 18 & Yes & CIRCE (BL24) & Academic & No & No & No & $1(1)$ \\
\hline 2016 & $\begin{array}{l}\text { Strong impact of the oxygen content in } \mathrm{Na} 3 \mathrm{~V} 2(\mathrm{PO} 4) 2 \mathrm{~F} 3-\mathrm{yO} \mathrm{y}(0 £ \text { y } £ \\
0.5) \text { on its structural and electrochemical properties }\end{array}$ & 10 & Yes & MSPD (BL04) & Academic & No & No & No & $1(1)$ \\
\hline 2016 & $\begin{array}{l}\text { Remote plasma cleaning of optical surfaces: Cleaning rates of different } \\
\text { carbon allotropes as a function of RF powers and distances }\end{array}$ & 7 & Yes & No beamtime & $\begin{array}{c}\text { No } \\
\text { beamtime }\end{array}$ & No & No & No & $1(1)$ \\
\hline 2005 & Operation of liquid-crystal displays for optical computing & 6 & Yes & No beamtime & $\begin{array}{c}\text { No } \\
\text { beamtime }\end{array}$ & No & No & No & $1(1)$ \\
\hline 2019 & $\begin{array}{l}\text { Evidence of the Coexistence of Multivalence Cerium Oxide Nano- } \\
\text { Particles in a Sodium Borate Glass }\end{array}$ & 8 & Yes & No beamtime & $\begin{array}{c}\text { No } \\
\text { beamtime }\end{array}$ & No & No & No & $1(1)$ \\
\hline 2015 & $\begin{array}{l}\text { Protein crystallization in short-peptide supramolecular hydrogels: a } \\
\text { versatile strategy towards biotechnological composite materials }\end{array}$ & 5 & No & XALOC (BL13) & Academic & No & No & No & $1(1)$ \\
\hline 2015 & $\begin{array}{l}\text { Influence of the chirality of short peptide supramolecular hydrogels in } \\
\text { protein crystallogenesis }\end{array}$ & 13 & No & XALOC (BL13) & Academic & No & No & No & $1(1)$ \\
\hline 2014 & $\begin{array}{l}\text { T Cells Kill Bacteria Captured by Transinfection from Dendritic Cells } \\
\text { and Confer Protection in Mice }\end{array}$ & 16 & Yes & $\begin{array}{l}\text { MISTRAL } \\
\text { (BL09) }\end{array}$ & Academic & No & No & No & $1(1)$ \\
\hline 2013 & $\begin{array}{l}\text { Structural and Conducting Features of Niobium-Doped Lanthanum } \\
\text { Tungstate, La27(W1-xNbx)5055.55- } \delta\end{array}$ & 7 & No & No beamtime & $\begin{array}{c}\text { No } \\
\text { beamtime }\end{array}$ & No & No & No & $1(1)$ \\
\hline 2015 & $\begin{array}{l}\text { Crystal Structure of Hcp from Acinetobacter baumannii: A Component of } \\
\text { the Type VI Secretion System }\end{array}$ & 6 & No & XALOC (BL13) & Academic & No & No & No & $1(1)$ \\
\hline 2015 & Towards a calcium-based rechargeable battery & 4 & No & MSPD (BL04) & Industrial & No & No & No & $1(1)$ \\
\hline 2014 & $\begin{array}{l}\text { Disruption of Allosteric Response as an Unprecedented Mechanism of } \\
\text { Resistance to Antibiotics }\end{array}$ & 8 & No & XALOC (BL13) & Academic & No & No & No & $1(1)$ \\
\hline
\end{tabular}

Source: Authors processing of Lens PatCite results. Note: In-house, academic and industrial are beamtime related. In-house refers to experiments carried out by ALBA staff, industrial to 
Figure 7 Matches between beamline, publications, patent documents and patent sectors

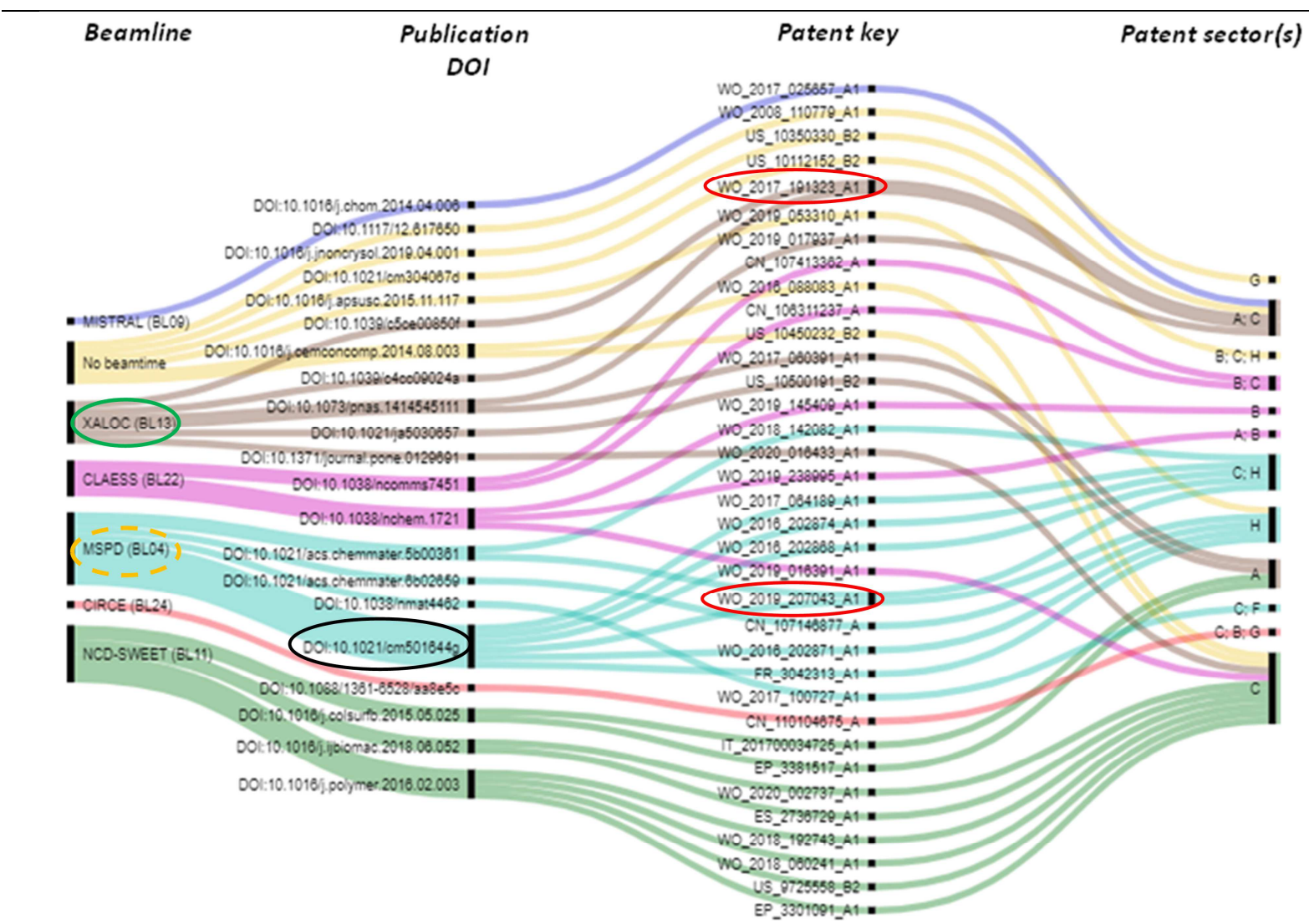

A - Human necessities; $B$ - Performing operations transporting; $C$ - Chemistry Metallurgy; $F$ - Mechanical engineering lighting heating; $G$ Physics; $H$ - Electricity *

Source: Authors processing of Lens PatCite results. Note: *According to International Patent Classification.

Our analysis also investigated the time-lapse occurring between the publication year of an article and the year this article is cited in the patent. In line with existing literature in the field (Finardi, 2011; Halevi and Moed, 2012) we found that this may differ substantially across the various fields of technology. Specifically, in the case of ALBA, we found a time lag ranging from less than one year (DOI:10.1016/j.jnoncrysol.2019.04.001) to six years (DOI:10.1038/nchem.1721, fuchsia bars in the chart below). This analysis sheds light on the following two time-related problems:

- First, publications can take months, and in some cases even years, to be published in scientific journals.

- Second, delays may occur between patent application and its publication ${ }^{24}$ as well as the time the patent is finally granted (not every patent application results in an issued patent).

\footnotetext{
${ }^{24}$ The patent application publication is not a granted patent. It is simply a published application.
} 


\section{Figure 8 Time Lags between publications and patents}

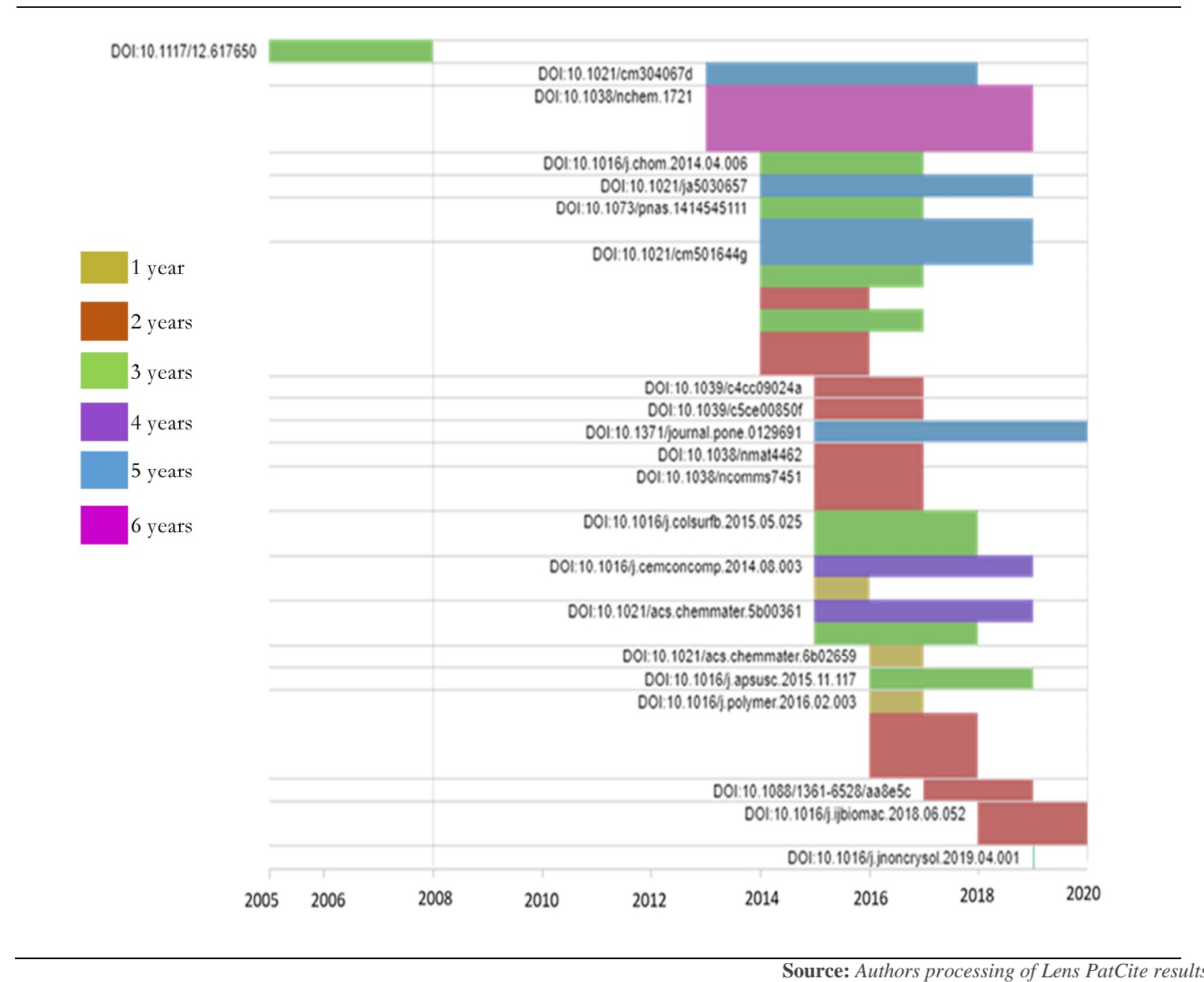

\section{Discussion and conclusions}

Assessing innovation impacts arising from a Research Infrastructure is not straightforward. The pathway from knowledge creation to innovation according to which these impacts may materialise is complex: it is split among different players, from scientific community to industrial actors (even if not directly involved in the experiments) and may take time and significant investments.

The methodology presented in this paper allowed for such a demanding task. By taking the example of ALBA Synchrotron Light source facility located in Barcelona, this paper traces and describes the impacts on (direct/indirect) users which materialise through a chain of downstream transmission mechanisms. Starting from the evaluation strategy proposed by Florio (2019) for assessing the innovation impacts generated by ALBA, our analysis built on the evidence collected through two surveys to direct and indirect users of ALBA, in-depth interviews as well as an analysis of patents' citations. By looking at the pathways materialising from the design to the performance of the experiment as well as to generation of the innovation output and its impacts, it sheds light on 
several aspects related to the impact of Research Infrastructures: the main innovation pathways, the gestation lag(s) as well as the research gap(s) of innovation.

This paper found that users from the scientific community limit their strategy to publishing in peer-reviewed journals or attending conferences, although the results from experiments carried out at ALBA synchrotron - generally by scientific and industrial communities individually - may have a potential application for industry. At that stage, their research is still far away from an immediate industrial application and therefore less attractive for industrial partnership. Also, once the experiment is completed, it is infrequent that the results are immediately used. As from users' knowledge, experiments carried out at ALBA mostly translate in publications and very rarely in patents or other intellectual property. In most cases, the experiment represents a step contributing to broader research, and therefore, it requires additional time and complementary research activities to create innovation with economic relevance, even when the user is from the private field. Nevertheless, the analysis of patent citations showed that the knowledge embodied in scientific publications has actually contributed to develop patents.

As concerns the gestation $\operatorname{lag}(\mathrm{s})$ of innovation, the evidence collected shows that the time needed to achieve innovation outputs varies depending on the type of research carried out, the research field/sector of activity of the user as well as the beamlines used. When the experiment is carried out by users from the scientific community, the pathways to innovations are faster in the case of research with application orientation or industrially relevant research in the field of chemistry, material science for energy/information technology, biology-life sciences and protein crystallography (from 1 to 5 years). A longer time may be required for experiments in the field of solid-state physics and materials science concerning structure, phase transitions, nanomaterials as well as in the field of instrumentation and techniques development. Even when the user is from the private field, the time to create the innovation depends on the sector of activity of the user. If the experiments are carried out by a manufacturer, 1-2 years may be needed to develop a new product or to improve an existing one. Instead, a longer time is required where the experiment is carried out by companies carrying out research which most likely operate on behalf of indirect users.

With regard the research gap(s) of innovation, we found that in order to develop an innovation output with economic or practical significance based on the results of the experiments carried out at ALBA synchrotron, additional activities carried out internally are needed for nearly half of the experiments carried out by survey's respondents from both the scientific community and private companies. Relatively less frequent are instead additional activities carried out by specialised companies or in other synchrotrons/research institutes. 
Overall, our analysis showed that experiments at synchrotron light sources usually do not directly generate innovations, but rather create knowledge embodied in scientific papers which in turn are used downstream for innovation purposes as documented by the analysis of citations in other papers and patents. While studying the initial linkages in this chain of cumulative effects, we have found that ALBA has the potential to create socio-economic value through some direct applications but mostly through the mediation of scientific papers that in turn enter in the process of knowledge creation.

The low outcome of industrial applications - shown by the case of ALBA - is not a surprise and can be explained by a number of factors, some of which are also worth to be considered for other synchrotron or light sources:

i. ALBA is committed to serve primarily the academic scientific community: the largest share of experiments (95\% on average) is carried out by the academia, only exceptionally in collaboration with industrial partners.

ii. At ALBA synchrotron - like in any other synchrotrons or light sources - the experiments carried out by the scientific community are selected on the basis of "scientific excellence" merit which is evaluated by a peer review exercise. Usually, the "scientific excellence" is cutting edge research that are often at low TRL or that intends to make a novel proof of concept. As a such, in many cases the experiments performed at the synchrotrons are ending up in no immediate technological applicability.

iii. Although applications from the industrial community (to ALBA facilities as well as to other light sources) are usually related to the development of an innovation which is closer to the market (a high TRL), they access the facility in a proprietary mode which guarantees full confidentiality. For this reason, they are not obliged to publish the results of their experiments and can decide to keep them confidential. As a consequence, tracking results of industrial applications (e.g., publications, citations or patents) is a challenge.

iv. Effects in terms of industrial applications from ALBA are expected to materialize and be higher in the next years considering that it is a young facility (in operation since 8 years) and not yet working at its full capacity (it may potentially host around 12 beamlines more). Moreover, experiments and publications have significantly increased over the recent years and they still need some time to generate effects. 


\section{REFERENCES}

- Åberg, Susanne, and Anna Bengtson. 2015. 'Does CERN procurement result in innovation?' Innovation: The European Journal of Social Science Research 28.3: 360-383.

- Ahmadpoor, M., \& Jones, B. F. (2017). The dual frontier: Patented inventions and prior scientific advance. Science, 357(6351), 583-587.

- Basberg, B. L. (1987). Patents and the measurement of technological change: a survey of the literature. Research policy, 16(2-4), 131-141.

- Batra, S., \& Tyagi, C. (2012). Comparative analysis of relational and graph databases. International Journal of Soft Computing and Engineering (IJSCE), 2(2), 509-512.

- Bousfield, D., McEntyre, J., Velankar, S., Papadatos, G., Bateman, A., Cochrane, G., ... \& Blomberg, N. 2016. Patterns of database citation in articles and patents indicate long-term scientific and industry value of biological data resources. F1000Research, 5. https://www.ncbi.nlm.nih.gov/pmc/articles/PMC4821287/

- Branstetter, L., \& Ogura, Y. (2005). Is academic science driving a surge in industrial innovation? Evidence from patent citations (No. w11561), National Bureau of Economic Research.

- Callaert, Julie, Van Looy, B., Verbeek, A., Debackere, K., \& Thijs, B.2006. 'Traces of prior art: An analysis of non-patent references found in patent documents'. Scientometrics, 69(1), 3-20.

- Castelnovo, P., Florio, M., Forte, S., Rossi, L., \& Sirtori, E. (2018). The economic impact of technological procurement for large-scale research infrastructures: Evidence from the Large Hadron Collider at CERN. Research Policy, 47(9), 1853-1867.

- Catalano, J. Florio, M. Vignetti, S. Pancotti, C., Gaston, G. and Sanchez, A. (2020), The pathways from experiments to innovation impacts: evidence from ALBA Synchrotron Light Facility, deliverable drafted in the framework of Horizon2020 RIPATHS project (grant agreement No. 777563), available at https://ri-paths.eu/wp-content/uploads/2020/06/T5.2_PilotIA-project-with-ALBA.pdf

- Comin, D., Licht, G., Pellens, M., and Schubert, T. (2018). Do Companies Benefit from Public Research Organizations? The Impact of the Fraunhofer Society in Germany (No. 2018/7). Lund University, CIRCLE-Center for Innovation, Research and Competences in the Learning Economy

- Council Regulation No 723/2009 of 25 June 2009, Community legal framework for a European Research Area, https://ec.europa.eu/research/infrastructures/pdf/council_regulation_eric.pdf

- European Commission (2017a). Horizon 2020, Work Programme 2016-2017. Available at http://ec.europa.eu/research/participants/data/ref/h2020/wp/2016_2017/main/h2020-wp1617infrastructures_en.pdf

- European Commission (2017b). The economic rationale for public R\&I funding and its impact. Policy Brief Series, Directorate-General for Research and Innovation.

- European Strategy Forum on Research Infrastructures (ESFRI): Innovation Working Group. (2018). Innovation-oriented cooperation of research infrastructures. Università degli studi di Milano, Dipartimento di Fisica. 
- European Strategy Forum on Research Infrastructures. (2010). Strategy Report on Research Infrastructures: Roadmap 2010.

- European Strategy Forum on Research Infrastructures: ESFRI White Paper (2020). Making science happen: a new ambition for Research Infrastructures in the European Research Area, prepared by Università degli studi di Milano, Dipartimento di Fisica.

- European Strategy Forum on Research Infrastructures: Long-Term Sustainibility Working Group. (2017). Long-term Sustainability of Research Infrastructures. Università degli studi di Milano, Dipartimento di fisica.

- European Union Regulation No 1291/2013 of the European Parliament and of the Council of 11 December 2013 establishing Horizon 2020 - the Framework Programme for Research and Innovation (2014-2020) and repealing Decision No 1982/2006/EC

- Fernández, M. T., Cabrero, A., Zulueta, M. A., \& Gómez, I. (1993). Constructing a relational database for bibliometric analysis. Research evaluation, 3(1), 56-62.

- Finardi, U. (2011). Time relations between scientific production and patenting of knowledge: The case of nanotechnologies. Scientometrics, 89(1), 37-50.

- Florio, M. (2019). Investing in Science: Social Cost-Benefit Analysis of Research Infrastructures. MIT Press.

- Florio, M., Giffoni, F., Giunta, A., \& Sirtori, E. (2018). Big science, learning, and innovation: evidence from CERN procurement. Industrial and Corporate Change, 27(5), 915-936.

- Fukuzawa, N., \& Ida, T. (2016). Science linkages between scientific articles and patents for leading scientists in the life and medical sciences field: The case of Japan. Scientometrics, 106(2), 629-644.

- Gazni, A. (2020). The growing number of patent citations to scientific papers: Changes in the world, nations, and fields. Technology in Society, 101276.

- Ginde, G., Saha, S., Mathur, A., Vamsi, H., Dey, S. R., \& Gambhire, S. S. (2018). Use of NoSQL database and visualization techniques to analyze massive scholarly article data from journals. arXiv preprint arXiv:1805.00390.

- Halevi, G., \& Moed, H.F. (2012). The technological impact of library science research: A patent analysis. In E. Archambault, Y. Gingras, \& V. Larivière (Eds.), Proceedings of 17th International Conference on Science and Technology Indicators (Vol.1, pp. 371-380), Montréal: ScienceMetrix and OST.

- Han, F., \& Magee, C. L. (2018). Testing the science/technology relationship by analysis of patent citations of scientific papers after decomposition of both science and technology. Scientometrics, 116(2), 767-796.

- Helman, A. Barberis, M., Vignetti, S., Catalano, J., Griniece, E., Kroll, H., Zenker, A., Martin C., (2020). Validated IA Model, deliverable 5.1 produced in the framework of H2020 project Research Infrastructure imPact Assessment paTHwayS (Grant agreement 777563), https://ripaths.eu/wp-content/uploads/2018/03/D5.1_Validated-IA-model.pdf

- Interreg Europe (2019). Policy challenges in exploiting research and innovation infrastructure: a Policy Brief from the Policy Learning Platform on Research and innovation, available at 
https://www.interregeurope.eu/fileadmin/user_upload/plp_uploads/policy_briefs/TO1_policy_bri ef_Research_and_innovation_infrastructure_01.pdf

- Jonkers, K., Derrick, G. E., Lopez-Illescas, C., \& Van den Besselaar, P. (2014). Measuring the scientific impact of e-research infrastructures: a citation based approach?. Scientometrics, 101(2), 1179-1194.

- Karki, M. M. S. (1997). Patent citation analysis: A policy analysis tool. World Patent Information, 19(4), 269-272.

- Mallig, N. (2010). A relational database for bibliometric analysis. Journal of Informetrics, 4(4), 564-580.

- Medhi, S., \& Baruah, H. K. (2017). Relational database and graph database: A comparative analysis. Journal of Process Management. New Technologies, 5(2), 1-9.

- OECD (2014). The Impacts of Large Research Infrastructures on Economic Innovation and on Society: Case Studies at CERN. https://www.oecd.org/sti/sci-tech/CERN-case-studies.pdf 18 .

- OECD (2019). Reference Framework for Assessing the Scientific and Socio-economic Impact of Research infrastructures, OECD Science, Technology and Industry Policy Paper (STI Policy Paper).

- OECD GSF (2014). International distributed research infrastructures: issues and options, https://www.oecd.org/sti/inno/international-distributed-research-infrastructures.pdf.

- OECD GSF (2016). OECD global science forum workshop on methodologies and tools for assessing socio-economic impact of research infrastructures. Summary Report prepared by Jean Moulin (consultant) for the Global Science Forum. Paris, 3 November 2015.

- Ribeiro, B., \& Shapira, P. (2020). Private and public values of innovation: A patent analysis of synthetic biology. Research Policy, 49(1), 103875.

- Schmoch, U. (1993). Tracing the knowledge transfer from science to technology as reflected in patent indicators. Scientometrics, 26(1), 193-211.

- Yamashita, Y. (2018). Exploring Characteristics of Patent-Paper Citations and Development of New Indicators. Scientometrics, 151.

- Zhao, Z. Y., \& Lei, X. P. (2013). Empirical analysis of the relationship between technology innovation and basic research. Current Science, 714-720. 